NBER WORKING PAPER SERIES

\title{
BUYERS, SELLERS AND MIDDLEMEN: \\ VARIATIONS ON SEARCH-THEORETIC THEMES
}

\author{
Yuet-Yee Wong \\ Randall Wright \\ Working Paper 17511 \\ http://www.nber.org/papers/w17511
NATIONAL BUREAU OF ECONOMIC RESEARCH
1050 Massachusetts Avenue
Cambridge, MA 02138
October 2011

Wright tanks the NSF and the Ray Zemon Chair in Liquid Assets at UW for support. The views expressed herein are those of the authors and do not necessarily reflect the views of the National Bureau of Economic Research.

NBER working papers are circulated for discussion and comment purposes. They have not been peerreviewed or been subject to the review by the NBER Board of Directors that accompanies official NBER publications.

(C) 2011 by Yuet-Yee Wong and Randall Wright. All rights reserved. Short sections of text, not to exceed two paragraphs, may be quoted without explicit permission provided that full credit, including $\odot$ notice, is given to the source. 
Buyers, Sellers and Middlemen: Variations on Search-Theoretic Themes

Yuet-Yee Wong and Randall Wright

NBER Working Paper No. 17511

October 2011

JEL No. D2,D4,D83

\begin{abstract}
$\underline{\text { ABSTRACT }}$
We study bilateral exchange, both direct trade and indirect trade that happens through chains of intermediaries or middlemen. We develop a model of this activity and present applications. This illustrates how, and how many, intermediaries get involved, and how the terms of trade are determined. We show how bargaining with one intermediary depends on upcoming negotiations with downstream intermediaries, leading to holdup problems. We discuss the roles of buyers and sellers in bilateral exchanges, and how to interpret prices. We develop a particular bargaining solution and relate it to other solutions. In addition to contrasting our framework with other models of middlemen, we discuss the connection to different branches of search theory. We also illustrate how bubbles can emerge in intermediation.
\end{abstract}

\author{
Yuet-Yee Wong \\ Binghamton University \\ Department of Economics \\ POB 6000 \\ Binghamton, NY 13902 \\ yywong01@gmail.com \\ Randall Wright \\ Department of Finance and Department of Economics \\ University of Wisconsin - Madison \\ Grainger Hall \\ 975 University Ave \\ Madison, WI 53706 \\ and NBER \\ rwright@bus.wisc.edu
}


"You sell your own works directly, Mr Nelson?" Siobhan asked.

"Dealers have got the market sewn up," Nelson spat. "Bloodsucking bastards that they are ..." Resurrection Men (1991), by Ian Rankin

\section{Introduction}

We study bilateral exchange, both direct trade, and indirect trade that happens through intermediaries, or middlemen. We develop a model of this activity and present several applications. The framework illustrates how, and how many, middlemen might get involved. Although there is much economic research on the topic, a neglected aspect that seems important to business practitioners is that there are often multiple middlemen engaged in getting goods from the originator to end user - e.g., from farmer to broker to distributor to retailer to consumer. ${ }^{1}$ A feature we emphasize is that the terms of trade one might negotiate with an intermediary depend on upcoming negotiations with the second, third and other downstream intermediaries. We call this bargaining with bargainers. We also have something to say about the roles of buyers and sellers - in particular, which are which - in bilateral exchange, and about the interpretation of prices. We develop a particular bargaining solution and discuss how it relates to other solutions. Additionally, we illustrate how bubbles can emerge in the value of inventories as they get traded across intermediaries.

In terms of related work, it was not so long ago that Rubinstein and Wolinsky (1987), hereafter RW, motivated their study as follows:

Despite the important role played by intermediation in most markets, it is largely ignored by the standard theoretical literature. This is because a study of intermediation requires a basic model that describes explicitly the trade frictions that give rise to the function of intermediation. But this is missing from the standard market models, where the actual process of trading is left unmodeled.

\footnotetext{
${ }^{1}$ As a special case of this example, taken from Cooke (2000), consider illegal drugs. As another example, Ellis (2009) describes the internet like this: "If a majority of the wholesale companies being advertised are not true wholesale companies, then what are they and where are they getting their products? They are likely just middleman operating within a chain of middleman. A middleman chain occurs when a business purchases its resale products from one wholesale company, who in turn purchases the products from another wholesale company, which may also purchase the products from yet another wholesale company, and so on."
} 
Subsequent studies attempt to rectify the situation by analyzing how middlemen affect the quality of matches, the time required to conduct transactions, the variety of goods on the market, bid-ask spreads, and other phenomena. RW themselves focus on search frictions, and for them, middlemen are agents who have an advantage over the original suppliers in the rate at which they meet buyers. Focusing instead on information frictions, Biglaiser (1993) and Li $(1998,1999)$ present models where middlemen are agents with expertise that allows them to distinguish high- from low-quality goods, and show how the presence of informed intermediaries helps to ameliorate lemons problems. In other papers (Camera 2001, Johri and Leach 2002, Shevchenko 2004, Smith 2004 and Watanabe 2010a,b), middlemen hold inventories of either more, or more types of, commodities that help buyers obtain their preferred goods more easily. ${ }^{2}$

In general, middlemen may either hold inventories, or act as market makers whose role is to get traders together, without buying and selling themselves (Yavas 1992, 1994, 1996; Gehrig 1993). Models of these activities in financial markets include Duffie, Garleanu and Pedersen (2005), Miao (2006), Weill (2007), Lagos and Rocheteau (2009) and Lagos, Rocheteau and Weill (2009). Many of these applications can be considered part of the New Monetarist economics surveyed by Nosal and Rocheteau (2010) and Williamson and Wright (2010a,b), defined by an endeavor to explicitly model the exchange process, and institutions that facilitate this process, including money, intermediaries, etc.. We say more later about the relationship between intermediation and money; for now we mention that early searchbased models of money like Kiyotaki and Wright (1989) not only make predictions about which objects emerge as media of exchange, as a function of their properties and of beliefs, they can also be used to think about which agents might act as middlemen.

Search theory is the right tool for analyzing intermediaries and related institutions because, as RW suggest, it models exchange explicitly. In a sense, this study is as much about search theory as it is about the substantive topic of middlemen. We set up our environment differently, in several ways, from previous studies. This is because we are less interested in

\footnotetext{
${ }^{2}$ Other related papers include Kalai, Postlewaite and Roberts (1978), Rust and Hall (2003), Masters (2007, 2008), Tse (2009) and Bose and Sengupta (2010).
} 
why middlemen have a role, in the sense that much of the analysis involves circumstances where trade must be intermediated. Instead, we focus on equilibrium exchange patterns with potentially long chains of intermediation, and the determination of the terms of trade along these chains. ${ }^{3}$ Still, for comparison, we present a version that generalizes RW. More ambitiously, we not only compare our framework with other models of middlemen, we also discuss the connection to other branches of search theory, and show how some ostensibly different models can be interpreted in one light. This leads to several questions about models of bilateral trade - including, who is the buyer and who is the seller, and what is the price? In terms of price determination, we focus on a particular bargaining solution that we think is attractive, but also give results for other bargaining solutions.

A recently popular activity that our model captures is flipping. ${ }^{4}$ According to Wikipedia, this is "purchasing a revenue-generating asset and quickly reselling (or 'flipping') it for profit." Although one can flip any asset, the moniker is usually applied to real estate, or sometimes IPO's. As regards our focus on intermediation chains, "Under the multiple investor flip, one investor purchases a property at below-market value, assigns or sells it quickly to a second investor, who subsequently sells it to the final consumer, closer to market value." Of course, "Profits from flipping real estate come from either buying low and selling high (often in a rapidly-rising market), or buying a house that needs repair and fixing it up before reselling." It is common to think that this activity may have something to do with the generation of price bubbles in housing and other markets, defined here as equilibria where prices differ from their fundamental values. As we said, the model is capable of generating bubble-like equilibria, if one sets it up just right. Part of the contribution is to show exactly what model ingredients are necessary to generate bubbles.

The rest of the paper is organized as follows. Section 2 lays out some basic assumptions and examples. Section 3 presents our extension of the standard RW model. Section 4 goes into detail concerning the dynamics of intermediation chains. Section 5 discusses bigger issues

\footnotetext{
${ }^{3}$ There is a somewhat related literature on production chains; see, e.g., Levine (2010) and the references contained therein.

${ }^{4}$ See Bayer, Geissler and Roberts (2011) for a recent empirical study and references to other work.
} 
of interpretation in this class of models, including the relation between distinct branches of the search literature. Section 6 takes up bubbles. Section 7 concludes.

\section{The Basic Model}

\subsection{General Assumptions}

Consider a set of agents $\mathcal{A}=\left\{A_{1}, A_{2}, \ldots A_{N}\right\}$, where $N \leq \infty$. They are spatially separated with the following connections: $A_{n}$ can meet, and hence trade, with $A_{n-1}$ and $A_{n+1}$ but no one else. We can represent the population as a graph with the set of nodes $\mathcal{A}$ connected as show in Figure 1. There are search frictions, which means it can take time and other resources for $A_{n}$ to meet $A_{n+1}$. There is an indivisible object $x$ in fixed supply, and a divisible object $y$ that anyone can produce at unit cost (i.e., the utility of producing $y$ units of this object is $-y)$. Only $A_{1}$ is endowed with $x$, and he can either try to trade it to $A_{2}$ in exchange for $y_{1}$, or consume it himself for utility $\gamma_{1}$. Hence, $\gamma_{1}$ is $A_{1}$ 's opportunity cost of trading (later we also consider production costs).

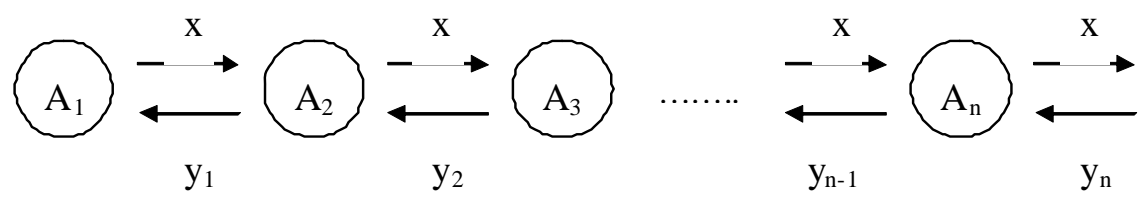

Figure 1: Population graph

Generally, if any agent $A_{n}$ acquires $x$ from $A_{n-1}$, he can either consume it for payoff $\gamma_{n}$, or try to trade it to $A_{n+1}$ for payoff $u\left(y_{n}\right)=y_{n}$. If $A_{1} \operatorname{trades} x$ to $A_{2}$ and $A_{2}$ trades it to $A_{3} \ldots$ before some $A_{N}$ eventually consumes it, we say that trade is intermediated and call $A_{2}, \ldots A_{N-1}$ intermediaries or middlemen. For most of what we do, it is assumed that $A_{n}$ exits the market after trading $x$ to $A_{n+1}$. If one wants to keep the economy going, one can replace every $A_{n}$ with a clone of himself after he exists. Alternatively, in Section 3 we recycle agents by allowing them to continue rather than exit after trade (see, e.g., Burdett and Coles 1999 for a discussion of cloning vs recycling in search models). 


\subsection{Example: $N=2$}

Consider $N=2$, or equivalently for this exercise, $N=\infty$ with $\gamma_{n}>0$ for $n \leq 2$ and $\gamma_{n}=0$ for all $n>2$, since this implies $x$ will never be traded beyond $A_{2}$ (but see Sec.6). This case admits no middlemen, but is still useful for illustrating our trading protocol. Suppose $A_{1}$ meets $A_{2}$ and $\gamma_{2}>\gamma_{1}$, as otherwise there are no gains from trade, and $A_{1}$ consumes $x$. Then we assume they play the following game.

Stage 1: $A_{1}$ moves by making an offer "give me $y_{1}$ for $x . "$

Stage 2: $A_{2}$ moves by accepting or rejecting, where:

- accept means the game ends;

- reject means we go to stage 3 .

Stage 3: Nature moves (a coin toss) with the property that:

- with probability $\theta_{1}, A_{1}$ makes $A_{2}$ a take-it-or-leave-it offer;

- with probability $1-\theta_{1}, A_{2}$ makes $A_{1}$ a take-it-or-leave-it offer.

Figure 2 shows the game tree. ${ }^{5}$ If the initial offer $y_{1}$ is accepted, $A_{1}$ gets payoff $y_{1}$ and $A_{2}$ gets $\gamma_{2}-y_{1}$. If $y_{1}$ is rejected, with probability $\theta_{1}, A_{1}$ gets the whole surplus leaving $A_{2}$ with his outside option 0 , and with probability $1-\theta_{1}, A_{1}$ gets his outside option $\gamma_{1}$ leaving $A_{2}$ with $\gamma_{2}-\gamma_{1}$. One subgame perfect equilibrium is: at stage $1, A_{1}$ makes $A_{2}$ his reservation offer, which means $A_{2}$ is indifferent between accepting and rejecting, and he accepts. If agents are risk neutral there is also a payoff-equivalent equilibrium where the initial offer is rejected

\footnotetext{
${ }^{5}$ We are not sure of the original use of this extensive form, but it is obviously related to Stahl (1972), Rubinstein (1982), Binmore (1987) and McCleod and Malcomson (1993), to name a few. The exact specification, with two rounds of bargaining, where the second has a coin toss to determine who makes the final offer, appeared in early versions of Cahuc, Postel-Vinay and Robin (2006), but they ultimately switched to a different game. See Marchesiani and Nosal (2010) for another recent application. But those applications assume linear utility. We say more about the issues when we come to nonlinear utility, since with linear utility, one can skip the first round and go right to a coin toss (e.g., as in Gale 1990 or Mortensen and Wright 2002). Since a coin toss induces risk, however, with risk aversion, skipping the first round is not bilaterally efficient. Generally, agents in the model would rather play our game, so we let them - since we are not comfortable imposing that they do something not in the bilateral core.
} 


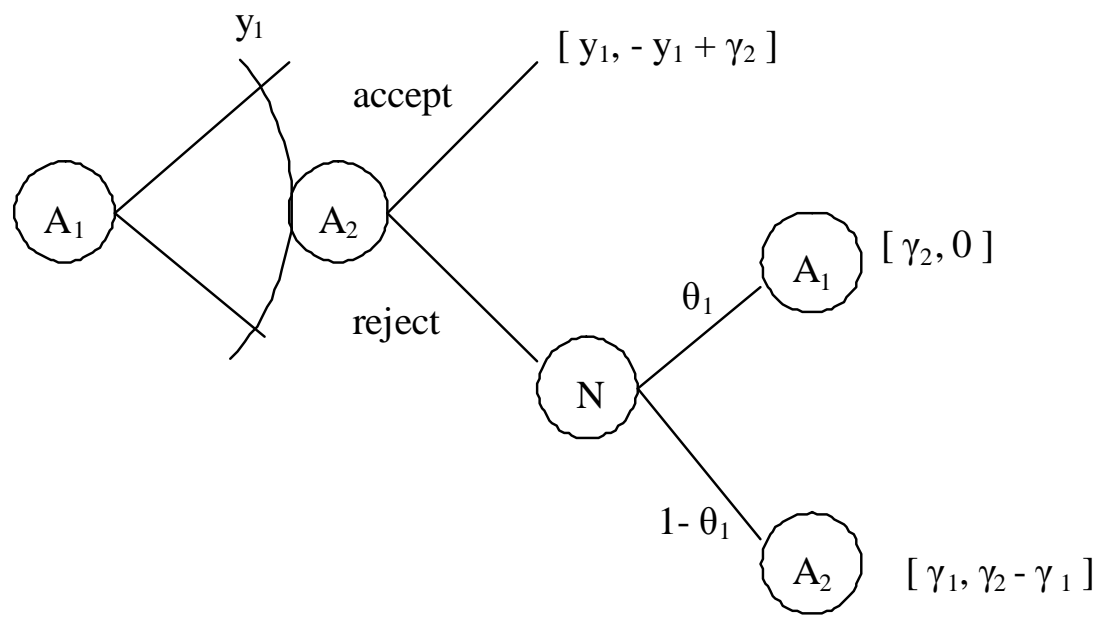

Figure 2: Game tree

and we move to Stage 3 , but one can refine that away by assuming either a probability $\varepsilon>0$ of an exogenous breakdown, or a discount factor $\delta<1$, between rounds. Or, as we do below, one can assume risk aversion. Then the equilibrium described above, with settlement in the first round, is unique, so we focus on it in what follows.

The condition making $A_{2}$ indifferent to accepting or rejecting $A_{1}$ 's offer is $\gamma_{2}-y_{1}=$ $\left(1-\theta_{1}\right)\left(\gamma_{2}-\gamma_{1}\right)$, or

$$
y_{1}=\left(1-\theta_{1}\right) \gamma_{1}+\theta_{1} \gamma_{2}
$$

The payoff for $A_{1}$ is $\gamma_{1}+\theta_{1}\left(\gamma_{2}-\gamma_{1}\right)$ and that for $A_{2}$ is $\left(1-\theta_{1}\right)\left(\gamma_{2}-\gamma_{1}\right)$. Now, agents are not compelled to participate, but as long as $\gamma_{2}>\gamma_{1}$ we have $\gamma_{1}+\theta_{1}\left(\gamma_{2}-\gamma_{1}\right) \geq \gamma_{1}$ and $\left(1-\theta_{1}\right)\left(\gamma_{2}-\gamma_{1}\right) \geq 0$, so their payoffs beat their outside options. Equivalently, defining the total surplus as the sum of payoffs minus outside options, $S_{12}=\left[\gamma_{1}+\theta_{1}\left(\gamma_{2}-\gamma_{1}\right)\right]-\gamma_{1}+$ $\left[\left(1-\theta_{1}\right)\left(\gamma_{2}-\gamma_{1}\right)\right]=\gamma_{2}-\gamma_{1}$, they trade as long as $S_{12} \geq 0$, which means $\gamma_{2} \geq \gamma_{1}$.

For comparison, consider the (generalized) Nash (1950) bargaining solution with threat points given by outside options:

$$
y_{1}=\arg \max _{y}\left(y-\gamma_{1}\right)^{\theta_{1}}\left(\gamma_{2}-y\right)^{1-\theta_{1}}
$$


Clearly (2) is solved by (1), so our game implements Nash's bargaining solution. It also implements Kalai's (1977) proportional bargaining solution, since it is the same as Nash in this example. ${ }^{6}$ We call the probability $\theta_{n}$ the bargaining power of $A_{n}$ when he plays with $A_{n+1}$, and allow $\theta_{n}$ to vary across agents because we believe it is an important element of intermediation activity - e.g., the fact that athletes, artists etc. employ agents may have to do with comparative advantages in bargaining. ${ }^{7}$

If it takes time and effort to meet $A_{n+1}$, the value of search for $A_{n}$ is $V_{n}$, where $V_{n}$ satisfies

$$
r V_{n}=\alpha_{n}\left(y_{n}-V_{n}\right)-c_{n},
$$

with $r$ the rate of time preference, $\alpha_{n}$ a Poisson arrival rate, and $c_{n}$ a flow search (or inventory or storage) cost. This implies

$$
V_{n}=\frac{\alpha_{n} y_{n}-c_{n}}{r+\alpha_{n}}
$$

and hence $A_{n}$ is willing to search for $A_{n+1}$ only if this exceeds his opportunity cost $\gamma_{n}$, or

$$
\left(r+\alpha_{n}\right) \gamma_{n} \leq \alpha_{n} y_{n}-c_{n}
$$

By (4) and (1), search by $A_{1}$ is viable if and only if

$$
c_{1}+\left(r+\alpha_{1}\right) \gamma_{1} \leq \alpha_{1}\left[\left(1-\theta_{1}\right) \gamma_{1}+\theta_{1} \gamma_{2}\right],
$$

which says the expected payoff covers the direct search cost and opportunity cost, appropriately capitalized. Since (5) implies $S_{12} \geq 0$, the binding constraint for trade is the viability of search, not the outside options.

\subsection{Example: $N=3$}

Now consider $N=3$ : an originator $A_{1}$; a potential end user $A_{3}$; and a potential middleman $A_{2}$. Equivalently, for this exercise, $N=\infty$ with $\gamma_{n}=0$ for all $n>3$. Note $A_{3}$ is a potential

\footnotetext{
${ }^{6}$ This is because of linear utility, and is not true once we introduce curvature. Clippel and Eliaz (2011) show that Nash and Kalai imply different outcomes in a similar setup, even with linear utility, but with information frictions.

${ }^{7} \mathrm{RW}$ use a simple surplus-splitting rule, corresponding to $\theta_{n}=1 / 2$ in our game when we have linear utility. They say "The reason that we abandon the strategic approach [in their earlier work] here is that it would greatly complicate the exposition without adding insights." But Binmore, Rubinstein and Wolinsky (1986) provide a strong argument in favor of the strategic approach - it makes the timing, threat points, etc. less ambiguous and arbitray - and we find it clarifies rather than complicates the analysis.
} 
end user in the sense that if he acquires $x$ he consumes it, since there is no one left to take it off his hands; it is possible, however, that $A_{1}$ prefers consuming $x$ rather than searching for $A_{2}$, or that $A_{2}$ prefers consuming it rather than searching for $A_{3}$. Different from some related models, here $A_{1}$ and $A_{3}$ cannot meet directly (this is relaxed in Sec. 3 ). Hence, the only way to get $x$ from $A_{1}$ to $A_{3}$ is via the intermediary $A_{2}{ }^{8}$

Given these assumptions, we ask which trades occur, and at what terms. Working backwards, if $A_{2}$ with $x$ meets $A_{3}$ then, as in the case $N=2$, we have

$$
y_{2}=\left(1-\theta_{2}\right) \gamma_{2}+\theta_{2} \gamma_{3}
$$

The payoffs from this trade for $A_{2}$ and $A_{3}$ are $y_{2}$ and $\left(1-\theta_{2}\right)\left(\gamma_{3}-\gamma_{2}\right)$, respectively. The total surplus is $S_{23}=\gamma_{3}-\gamma_{2}$, and they trade as long as $\gamma_{3} \geq \gamma_{2}$. More stringently, for search by $A_{2}$ to be viable we require $V_{2} \geq \gamma_{2}$, or

$$
c_{2}+\left(r+\alpha_{2}\right) \gamma_{2} \leq \alpha_{2}\left[\left(1-\theta_{2}\right) \gamma_{2}+\theta_{2} \gamma_{3}\right]
$$

If (7) holds then, upon acquiring $x, A_{2}$ looks to trade it to $A_{3}$; if (7) fails then $A_{2}$ consumes $x$ himself and $A_{3}$ is irrelevant.

So, suppose (7) holds, and back up to where $A_{1}$ meets $A_{2}$. When $A_{1}$ makes his initial offer, $A_{2}$ 's indifference condition is $-y_{1}+V_{2}=\left(1-\theta_{1}\right)\left(V_{2}-\gamma_{1}\right)$. Inserting $V_{2}$, we have

$$
y_{1}=\left(1-\theta_{1}\right) \gamma_{1}+\theta_{1} \frac{\alpha_{2} y_{2}-c_{2}}{r+\alpha_{2}}
$$

The payoffs for $A_{1}$ and $A_{2}$ are $y_{1}$ and $\left(1-\theta_{1}\right)\left(\frac{\alpha_{2} y_{2}-c_{2}}{r+\alpha_{2}}-\gamma_{1}\right)$, respectively, and $S_{12} \geq 0$ if and only if

$$
c_{2} \leq-\gamma_{1}\left(r+\alpha_{2}\right)+\alpha_{2}\left[\theta_{2} \gamma_{3}+\left(1-\theta_{2}\right) \gamma_{2}\right]
$$

More stringently, for search by $A_{1}$ to be viable we require $V_{1} \geq \gamma_{1}$, or using (6) and (8)

$$
c_{1} \leq-\left(r+\alpha_{1}\right) \gamma_{1}+\alpha_{1}\left\{\left(1-\theta_{1}\right) \gamma_{1}+\theta_{1} \frac{\alpha_{2}\left[\left(1-\theta_{2}\right) \gamma_{2}+\theta_{2} \gamma_{3}\right]-c_{2}}{r+\alpha_{2}}\right\} .
$$

\footnotetext{
${ }^{8}$ Thus, we cannot ask here why the market doesn't cut out the middlemen - or, in more modern jargon, why there isn't disintermediation. On that issue, practioners say this: "why doesn't every wholesaler just buy from the manufacture and get the deepest discount? The answer is simple - not all wholesalers (or companies claiming to be wholesalers) can afford to purchase the minimum bulk-order requirements that a manufacture requires. Secondly, many manufactures only do business with companies that are established" (Ellis 2009). We do not model this explicitly, but it might be worth pursuing in future work.
} 
Summarizing, after some algebra, for $x$ to pass from $A_{1}$ to $A_{2}$ to $A_{3}$ we require

$$
\begin{aligned}
\left(r+\alpha_{2}\right) c_{1}+\alpha_{1} \theta_{1} c_{2} & \leq-\left(r+\alpha_{1} \theta_{1}\right)\left(r+\alpha_{2}\right) \gamma_{1}+\alpha_{1} \theta_{1} \alpha_{2}\left(1-\theta_{2}\right) \gamma_{2}+\alpha_{1} \theta_{1} \alpha_{2} \theta_{2} \gamma_{3} \\
c_{2} & \leq-\left(r+\alpha_{2} \theta_{2}\right) \gamma_{2}+\alpha_{2} \theta_{2} \gamma_{3}
\end{aligned}
$$

If the inequality in (10) is reversed then $A_{2}$ consumes $x$ if he gets it, and he gets it if

$$
c_{1} \leq-\left(r+\alpha_{1} \theta_{1}\right) \gamma_{1}+\alpha_{1} \theta_{1} \gamma_{2}
$$

since this makes search by $A_{1}$ viable when $A_{2}$ consumes $x \cdot{ }^{9}$ As a special case, when frictions vanish, in the sense that $r \rightarrow 0$ and $c_{n} \rightarrow 0$, search by $A_{2}$ is viable if and only if $\gamma_{3} \geq \gamma_{2}$. If $A_{2}$ searches, in this case, search by $A_{1}$ is viable if and only if $\gamma_{1} \leq\left(1-\theta_{2}\right) \gamma_{2}+\theta_{2} \gamma_{3}$; and if $A_{2}$ does not search, then search by $A_{1}$ is viable if and only if $\gamma_{2} \geq \gamma_{1}$.

To develop some more economic intuition, consider the case where we do not take search frictions to 0 , so that $r>0$ and $c_{n}>0$, but suppose $\gamma_{2}=0$ so that $A_{2}$ is a pure middleman with no desire to consume $x$ himself. If $A_{2}$ acquires $x$ he searches for $A_{3}$ if the expected payoff exceeds the search cost, $\alpha_{2} \theta_{2} \gamma_{3} \geq c_{2}$. If this inequality is reversed $A_{2}$ does not want $x$, and the market shuts down. But if $\alpha_{2} \theta_{2} \gamma_{3} \geq c_{2}$, so that $A_{2}$ would search for $A_{3}$, then $A_{1}$ searches for $A_{2}$ if and only if

$$
\left(r+\alpha_{2}\right) c_{1}+\alpha_{1} \theta_{1} c_{2} \leq-\left(r+\alpha_{1} \theta_{1}\right)\left(r+\alpha_{2}\right) \gamma_{1}+\alpha_{1} \theta_{1} \alpha_{2} \theta_{2} \gamma_{3}
$$

In words, the RHS is $A_{1}$ 's expected share of $A_{2}$ 's expected share of the end user's payoff, net of his opportunity cost, while the LHS is $A_{1}$ 's direct search cost and the amount he has to compensate $A_{2}$ for $A_{2}$ 's search costs, all appropriately capitalized.

If $\gamma_{2}=0$ and $r \rightarrow 0, c_{n} \rightarrow 0$, then $A_{1}$ searches for $A_{2}$ who searches for $A_{3}$ if and only if $\theta_{2} \gamma_{3} \geq \gamma_{1}$. The key point here is that $\gamma_{3}>\gamma_{1}$ is not enough to get $x$ from $A_{1}$ to $A_{3}$, even when $\gamma_{2}, r$ and $c_{n}$ are negligible, due to a holdup problem. Potential middleman $A_{2}$ knows that $A_{3}$ is willing to give anything up to $\gamma_{3}$ to get $x$, and $A_{1}$ would be willing to let it go for as little as $\gamma_{1}$, which sounds like there is a deal to be done. But when $A_{2}$ meets $A_{3}$ he only gets

\footnotetext{
${ }^{9}$ To be clear, reversing the inequality in (11) means $A_{1}$ will not search for $A_{2}$ given that $A_{2}$ consumes $x$, but search by $A_{1}$ may still be viable if $A_{2}$, instead of consuming it, flips $x$ to $A_{3}$.
} 
$y_{2}=\theta_{2} \gamma_{3}$. He may protest he needs more just to cover his cost, $y_{1}=\left(1-\theta_{1}\right) \gamma_{1}+\theta_{1} \theta_{2} \gamma_{3}$. Being educated in economics, however, $A_{3}$ would (implicitly) counter that this cost is sunk and thus irrelevant in the negotiations. So $A_{2}$ will not intermediate the deal unless $\theta_{2} \gamma_{3} \geq \gamma_{1}$. This is a market failure, due to lack of commitment. If $A_{3}$ and $A_{2}$ could sign a binding ex ante contract, the former could agree to pay the latter at least enough to cover his costs. Such commitment is proscribed here: as in many search models, it seems reasonable to say you cannot contract with someone before you contact someone.

RW specify a clever way to potentially get around such holdup problems: have $A_{2}$ get $x$ from $A_{1}$, but only pay him after he sellers it. RW call this consignment. Then when $A_{2}$ and $A_{3}$ trade, $y_{1}$ it is not sunk. Of course, this only works if $A_{2}$ and $A_{1}$ can make contact after $A_{2}$ trades with $A_{3}$. If they can, then when $A_{2}$ meets $A_{3}$, the indifference condition is $\gamma_{3}-y_{2}=\left(1-\theta_{2}\right)\left(\gamma_{3}-\gamma_{2}-y_{1}\right)$. So when $A_{1}$ meets $A_{2}$, knowing he will not get $y_{1}$ until $A_{2}$ retrades, his offer making $A_{2}$ indifferent is $V_{2}-\frac{\alpha_{2}}{r+\alpha_{2}} y_{1}=\left(1-\theta_{1}\right)\left(V_{2}-\gamma_{1}\right)$. This implies

$$
\begin{aligned}
y_{1} & =\frac{\theta_{1}\left[\alpha_{2} \theta_{2} \gamma_{3}+\alpha_{2}\left(1-\theta_{2}\right) \gamma_{2}-c_{2}\right]+\left(1-\theta_{1}\right)\left(r+\alpha_{2}\right) \gamma_{1}}{\alpha_{2}\left[1-\theta_{1}\left(1-\theta_{2}\right)\right]} \\
y_{2} & =\frac{\alpha_{2}\left[\theta_{2} \gamma_{3}+\left(1-\theta_{2}\right) \gamma_{2}\right]-\left(1-\theta_{2}\right)\left[\theta_{1} c_{2}-\left(1-\theta_{1}\right)\left(r+\alpha_{2}\right) \gamma_{1}\right]}{\alpha_{2}\left[1-\theta_{1}\left(1-\theta_{2}\right)\right]}
\end{aligned}
$$

Notice $y_{2}>y_{1}$, so $A_{2}$ now not only covers his cost, he makes a profit. One can work out the viability conditions for $A_{1}$ to search given $A_{2}$ searches, and for $A_{1}$ to search given $A_{2}$ consumes $x$, just like we did for the model without consignment. ${ }^{10}$

Putting this all together, Figure 3 illustrates the equilibria that obtain in different regions of $\left(c_{1}, c_{2}\right)$ space for the models with and without consignment, partitioned by dashed and solid lines, respectively. Clearly, with consignment, the market is more likely to be active, and one can check that both middlemen and sellers get higher payoffs. We do not think either version of the model is superior, however: either consignment is feasible, and hence it

\footnotetext{
${ }^{10}$ For the record, with consignment the conditions for both $A_{1}$ and $A_{2}$ to search are:

$0 \geq c_{2}-\alpha_{2} \theta_{2} \gamma_{3}-\left(1-\theta_{2}\right)\left(1-\theta_{1}\right)\left(r+\alpha_{2}\right) \gamma_{1}+\left\{\left(r+\alpha_{2}\right)\left[1-\theta_{1}\left(1-\theta_{2}\right)\right]-\alpha_{2}\left(1-\theta_{2}\right)\right\} \gamma_{2}$

$0 \geq c_{1}\left(r+\alpha_{2}\right)\left[1-\theta_{1}\left(1-\theta_{2}\right)\right]+\alpha_{1} \theta_{1} c_{2}-\alpha_{1}\left[\left(1-\theta_{1}\right)\left(r+\alpha_{2}\right) \gamma_{1}+\theta_{1}\left\{\alpha_{2}\left[\theta_{2} \gamma_{3}+\left(1-\theta_{2}\right) \gamma_{2}\right]\right\}\right]$ $+\left(r+\alpha_{1}\right)\left(r+\alpha_{2}\right)\left[1-\theta_{1}\left(1-\theta_{2}\right)\right] \gamma_{1}$.
}

And the condition for $A_{1}$ to search given $A_{2}$ consumes $x$ is the same condition as in the model without consignment. Details of these calculations, which are straightforward but tedious, are available on request. 


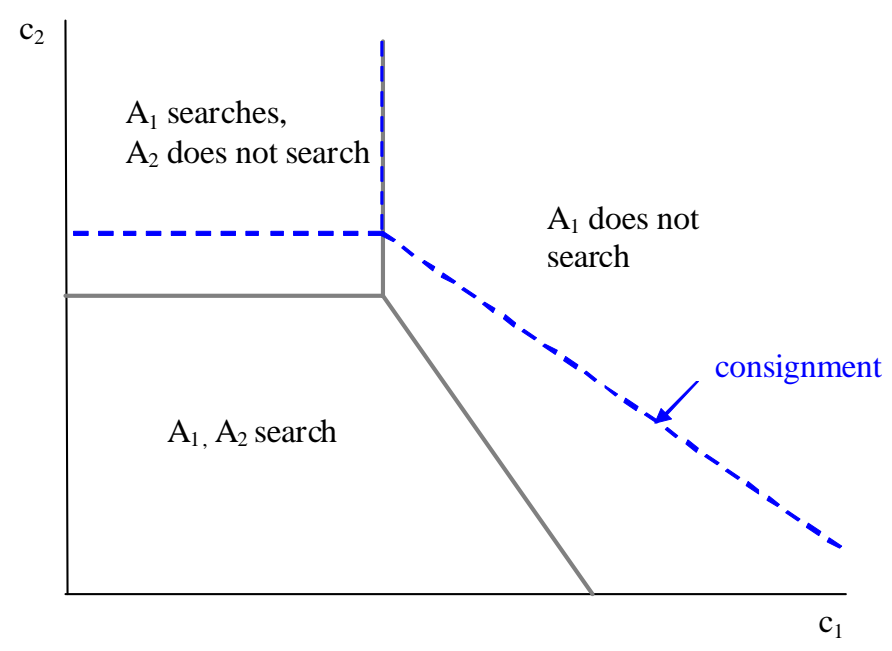

Figure 3: Equilibrium with and without Consignment

should be used, or it is not (say, if the physical environment is such that $A_{1}$ deals with $A_{2}$ just the once, never to meet again, which certainly seems relevant in some contexts). Rather than say one model is better, we merely compare outcomes in the two cases. A general conclusion we draw from the model is that whether exchange even gets off the ground, and the terms of trade when it does, depend on not only fundamentals and bargaining power in any one trading opportunity, but also on these parameters in downstream opportunities. Thus, the gains from trade between $A_{1}$ and $A_{2}$, e.g., depend on $A_{2}$ 's bargaining power when he later meets $A_{3}$. This is what we mean by bargaining with bargainers.

\section{Alternative Specification}

Consider a slightly different setup, designed to be closer to RW, where again there are $N=3$ types but now there are many agents of each type. Again, the types are called originators $A_{1}$, potential middlemen $A_{2}$, and potential end users $A_{3}$, with $\gamma_{1}=\gamma_{2}=0$ and $\gamma_{3}=\gamma>0$. Although there is no opportunity cost of trading $x$ for $A_{1}$ when $\gamma_{1}=0$, we allow a production cost $k \geq 0$. But the key difference from our baseline specification is that now anyone can meet anyone else. The main object of the analysis, in addition to determining if the market 
is even open, is to ascertain when middlemen are active, since $A_{1}$ has the option of trying to trade directly with $A_{3}$. Also, now we assume all agents continue in, rather than exit from, the market after a trade. Let $\pi_{n}$ be the measure of type $n$ agents, with $\pi_{1}+\pi_{2}+\pi_{3}=1$, and let $\alpha_{n n^{\prime}}$ be the rate at which $A_{n}$ meets $A_{n^{\prime}} .^{11}$ Let $\sigma_{n} \in\{0,1\}$ indicate whether or not $A_{n}$ searches, $n=1,2$, and let $\mu \in\{0,1\}$ indicate whether or not $A_{1}$ trades with $A_{2}$. Let $m$ be the steady state probability that $A_{2}$ is in possession of $x$, and to keep track of inventories, for middlemen, write $V_{2 i}$ where $i \in\{0,1\}$.

The steady state value of $m$ equates the inflow and outflow of inventories, $m \alpha_{23}=$ $(1-m) \alpha_{21} \sigma_{1} \mu$, which solves for

$$
m=\frac{\pi_{1} \alpha_{12} \sigma_{1} \mu}{\pi_{2} \alpha_{23}+\pi_{1} \alpha_{12} \sigma_{1} \mu} .
$$

Taking $m$ as given, the value functions satisfy

$$
\begin{aligned}
r V_{1} & =\alpha_{12}(1-m) \mu\left[y_{12}-V_{1}+\sigma_{1}\left(V_{1}-k\right)\right]+\alpha_{13}\left[y_{13}-V_{1}+\sigma_{1}\left(V_{1}-k\right)\right]-c_{1} \\
r V_{3} & =\sigma_{1} \alpha_{31}\left(\gamma-y_{13}\right)+\sigma_{2} \alpha_{32} m\left(\gamma-y_{23}\right) \\
r V_{20} & =\sigma_{1} \alpha_{21} \mu\left(\sigma_{2} V_{21}-V_{20}-y_{12}\right) \\
r V_{21} & =\alpha_{23}\left(y_{23}+V_{20}-V_{21}\right)-c_{2},
\end{aligned}
$$

where $y_{n n^{\prime}}$ is the bargaining outcome between $n$ and $n^{\prime}$, and we note production cost $k$ must be paid each time $A_{1}$ begins to search. These equations give the values of search; for $n=1,2$, the value of $x$ is then $\max \left\{0, V_{n}\right\}$. The indifference conditions in bargaining are

$$
\begin{aligned}
\gamma-y_{13} & =\left(1-\theta_{13}\right)\left[\gamma-V_{1}+\sigma_{1}\left(V_{1}-k\right)\right] \\
\gamma-y_{23} & =\left(1-\theta_{23}\right)\left(\gamma+V_{20}-V_{21}\right) \\
\sigma_{2} V_{21}-V_{20}-y_{12} & =\left(1-\theta_{12}\right)\left[\sigma_{2} V_{21}-V_{20}-V_{1}+\sigma_{1}\left(V_{1}-k\right)\right] .
\end{aligned}
$$

A steady state equilibrium here is given by values for the $V$ 's, $y$ 's and $m$ solving (14)-(21), along with a strategy profile $\mathbf{s}=\left(\sigma_{1}, \mu, \sigma_{2}\right)$ satisfying best-response conditions: (i) $\sigma_{1}=1$ if

\footnotetext{
${ }^{11} \mathrm{As}$ in RW, since the number of meetings between $n$ and $n^{\prime}$ is the same as the number between $n^{\prime}$ and $n$, we have the identities $\pi_{1} \alpha_{12}=\pi_{2} \alpha_{21}, \pi_{2} \alpha_{23}=\pi_{3} \alpha_{32}$ and $\pi_{3} \alpha_{31}=\pi_{1} \alpha_{13}$ (one can think of the $\pi$ 's as primitives, putting restrictions on the $\alpha$ 's, or vice-versa).
} 
$V_{1}>k$ and $\sigma_{1}=0$ if $V_{1}<k$; (ii) $\sigma_{2}=1$ if $V_{2}>0$ and $\sigma_{2}=0$ if $V_{2}<0$; and (iii) $\mu=1$ if $S_{12}>0$ and $\mu=0$ if $S_{12}<0$, where $S_{12}=\sigma_{2} V_{21}-V_{20}-V_{1}+\sigma_{1}\left(V_{1}-k\right)$. There are 8 possible pure-strategy profiles, enumerated in Table 1 . For each $\mathbf{s}$ in the columns we list parameter conditions that make each element a best response, using the following notation:

$$
\begin{aligned}
\bar{c}_{1} & =\alpha_{13} \theta_{13} \gamma \text { and } \widetilde{c}_{1}=\bar{c}_{1}-k\left(r+\alpha_{13} \theta_{13}\right) \\
\bar{c}_{2} & =\alpha_{23} \theta_{23} \gamma \text { and } \widetilde{c}_{2}=\bar{c}_{2}-k\left(r+\alpha_{23} \theta_{23}\right) \\
h\left(c_{1}\right) & =\widetilde{c}_{2}+\left(\widetilde{c}_{1}-c_{1}\right) \frac{r+\alpha_{23} \theta_{23}+\alpha_{21}\left(1-\theta_{12}\right)}{\alpha_{12} \theta_{12}(1-m)} \\
g\left(c_{1}\right) & =\widetilde{c}_{2}+\left(\widetilde{c}_{1}-c_{1}\right) \frac{r+\alpha_{23} \theta_{23}}{\alpha_{12} \theta_{12}} \\
f\left(c_{1}\right) & =\bar{c}_{2}-\left(\bar{c}_{1}-c_{1}\right) \frac{r+\alpha_{23} \theta_{23}}{r+\alpha_{13} \theta_{13}} \\
p_{1} & =\widetilde{c}_{1}-k \frac{r \alpha_{12} \theta_{12}(1-m)}{r+\alpha_{21}\left(1-\theta_{12}\right)} \\
p_{2} & =\bar{c}_{2}-k \frac{\alpha_{23} \theta_{23} \alpha_{21}\left(1-\theta_{12}\right)}{r+\alpha_{21}\left(1-\theta_{12}\right)} .
\end{aligned}
$$

\begin{tabular}{|c|c|c|c|c|}
\hline & \multicolumn{3}{|c|}{ Best Response Conditions } & Notes \\
\hline $\mathbf{s}$ & $\sigma_{1}$ & $\mu$ & $\sigma_{2}$ & \\
\hline$(0,0,0)$ & $\widetilde{c}_{1} \leq c_{1}$ & $\bar{c}_{1} \geq c_{1}$ & $\bar{c}_{2} \leq c_{2}$ & measure 0 if $k=0$ \\
\hline$(0,0,1)$ & $\widetilde{c}_{1} \leq c_{1}$ & $f\left(c_{1}\right) \leq c_{2}$ & $\bar{c}_{2} \geq c_{2}$ & measure 0 if $k=0$ \\
\hline$(0,1,0)$ & not binding & $\bar{c}_{1} \leq c_{1}$ & $\bar{c}_{2} \leq c_{2}$ & \\
\hline$(0,1,1)$ & $g\left(c_{1}\right) \leq c_{2}$ & $f\left(c_{1}\right) \geq c_{2}$ & $\bar{c}_{2} \geq c_{2}$ & \\
\hline$(1,0,0)$ & $\widetilde{c}_{1} \geq c_{1}$ & not binding & $\bar{c}_{2} \leq c_{2}$ & \\
\hline$(1,0,1)$ & $\widetilde{c}_{1} \geq c_{1}$ & $\widetilde{c}_{2} \leq c_{2}$ & $\bar{c}_{2} \geq c_{2}$ & measure 0 if $k=0$ \\
\hline$(1,1,0)$ & $p_{1} \geq c_{1}$ & $k=0$ & $p_{2} \leq c_{2}$ & measure 0 if $k>0$ \\
\hline$(1,1,1)$ & $h\left(c_{1}\right) \geq c_{2}$ & $\widetilde{c}_{2} \geq c_{2}$ & not binding & \\
\hline
\end{tabular}

Table 1: Candidate equilibria

Table 1 contains a lot of information, because it covers all 8 cases, but it is actually easy to understand. Consider $\mathbf{s}=(0,0,0)$, where $A_{1}$ doesn't search, $A_{1}$ wouldn't trade with $A_{2}$ if they were to meet, and $A_{2}$ wouldn't search if he had $x$. As indicated, for $\sigma_{1}=0$ to be a best response we require $V_{1} \leq k$, which after routine algebra reduces to $\widetilde{c}_{1} \leq c_{1}$, given other agents' strategies; for $\mu=0$ to be a best response we require $S_{12} \leq 0$, which reduces to $\bar{c}_{1} \geq c_{1}$; and for $\sigma_{2}=0$ to be a best response we require $V_{2} \leq 0$, which reduces to $\bar{c}_{2} \leq c_{2}$. In the last column we mention some properties of the candidate equilibria, e.g., for $\mathbf{s}=(0,0,0)$ 


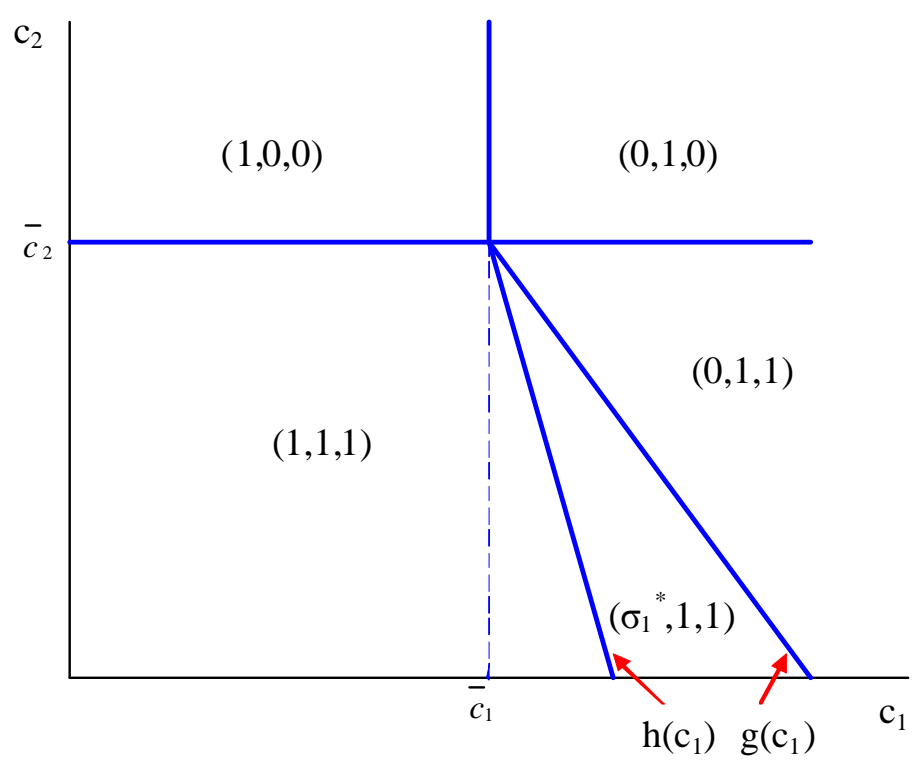

Figure 4: Equilibria with $k=0$

we note that $k=0$ implies $\widetilde{c}_{1}=\bar{c}_{1}$, which is satisfied only on a set of measure zero in parameter space. In discussing the results, we focus on economics, with algebra available on request. Basically, all the economics can be seen in $\left(c_{1}, c_{2}\right)$ space using Figure 4, drawn using the easily-verified results $h(0)>g(0)$ and $h\left(\bar{c}_{1}\right)=g\left(\bar{c}_{1}\right)=\bar{c}_{2}$.

To facilitate the presentation, we begin with $k=0$, which limits the types of equilibria that can exist. First we deal with equilibria with $\sigma_{1}=0$, where $A_{1}$ does not search and the market shuts down. Even if $\sigma_{1}=0$, we must specify as part of the equilibrium whether $A_{1}$ and $A_{2}$ would trade if they were to meet, and whether $A_{2}$ would search if he acquired $x$, off the equilibrium path (subgame perfection). There are two possible equilibria where $A_{1}$ does not search, $\mathbf{s}=(0,1,0)$ and $\mathbf{s}=(0,1,1)$, as Figure 4 shows. ${ }^{12}$ In each case $A_{1}$ and $A_{2}$ would trade if they were to meet, and in one $A_{2}$ would search while in the other he would not. Naturally, these no-trade outcomes occur when $c_{1}$ and $c_{2}$ are above certain thresholds. This is not surprising; the point of the analysis is to determine exactly how the thresholds depend on search and bargaining parameters, the $\alpha$ 's and $\theta$ 's, and the fundamental value $\gamma$.

\footnotetext{
${ }^{12}$ There are two other candidate equilibria where $\sigma_{1}=0, \mathbf{s}=(0,0,0)$ and $\mathbf{s}=(0,0,1)$, but they exist only for parameters in a set of measure zero when $k=0$.
} 
When $c_{1}$ is lower but $c_{2}$ still high, $\mathbf{s}=(1,0,0)$ is an equilibrium, where $A_{1}$ trades with $A_{3}$ but not $A_{2}$. Middlemen are inactive in this equilibrium, and $A_{2}$ would not search even if he had $x$. Algebra implies $\sigma_{1}=1$ is a best response if and only if $\bar{c}_{1} \geq c_{1}$, and $\sigma_{2}=0$ is a best response if and only if $\bar{c}_{2} \leq c_{2}$. There is no intermediation because $A_{2}$ has high search costs $\left(c_{2} / \gamma\right.$ is big), meets $A_{3}$ infrequently ( $\alpha_{23}$ is small), or bargains poorly ( $\theta_{23}$ is low). When $c_{1}$ and $c_{2}$ are both lower, however, as Figure 4 shows, $\mathbf{s}=(1,1,1)$ is an equilibrium, where $A_{1}$ searches and trades with $A_{3}$ or $A_{2}$, and $A_{2}$ searches for $A_{3}$ when he gets $x$. Now there is intermediation. Again, it is routine to check the best response conditions, which reduce to $h\left(c_{1}\right) \geq c_{2}$ and $\bar{c}_{2} \geq c_{2}$. The diagonal line $h\left(c_{1}\right)$ represents how $A_{1}$ 's search decision depends on $c_{2}$, because $y_{12}$ depends on $A_{2}$ 's expected cost and benefit from search (another instance of downstream bargaining affecting negotiations). Of particular interest is the region where $c_{1}>\bar{c}_{1}$ and $c_{2}<h\left(c_{1}\right)$, where the market is active only because of intermediation - i.e., if $A_{2}$ were absent all trade would cease.

This exhausts the set of possible pure-strategy equilibria. ${ }^{13}$ As Figure 4 shows, the outcome is essentially unique - i.e., the regions do not overlap - but there is an empty area between $c_{2}=h\left(c_{1}\right)$ and $c_{2}=g\left(c_{1}\right)$, where pure-strategy equilibria do not exist. The problem is that when $\sigma_{1}=1$ the steady state distribution of inventories held by $A_{2}$, summarized by $m$, is such that $V_{1}<k$, so $A_{1}$ does not want to search, and when $\sigma_{1}=0$ the steady state $m$ is such that $V_{1}>k$, so $A_{1}$ does want to search. In Appendix A, we show how to construct the natural mixed-strategy equilibrium that fills in this region, with $\sigma_{1}=\sigma_{1}^{*} \in(0,1)$ and $V_{1}=k$, meaning either $A_{1}$ agents randomizes, or some search and others do not. This completes the analysis for $k=0$.

The results are similar, if algebraically more intense, when $A_{1}$ has production cost $k>$ 0, as shown in Figure 5. Compared to Figure 4, three additional types of pure-strategy equilibrium pop up in the region $\left[\bar{c}_{1}, \widetilde{c}_{1}\right] \times\left[\bar{c}_{2}, \widetilde{c}_{2}\right]$, which was a non-issue with $k=0$, because then $\bar{c}_{j}=\widetilde{c}_{j}$. These include two new no-trade outcomes, $(0,0,0)$ and $(0,0,1)$, plus a new

\footnotetext{
${ }^{13}$ Actually, a minor technicality is that when equilibrium $(1,0,0)$ exists, so does $(1,1,0)$. It may seem strange that $A_{2}$ trades for $x$ and then neither searches nor consumes $x$, but this is an equilibrium since in this case $y_{12}=0$ and $A_{1}$ has production cost $k=0$. Since this cannot happen for any $k>0$, we ignore it. Any other candidate equilibrium in Table 1 exists at most for parameters in a set of measure zero.
} 


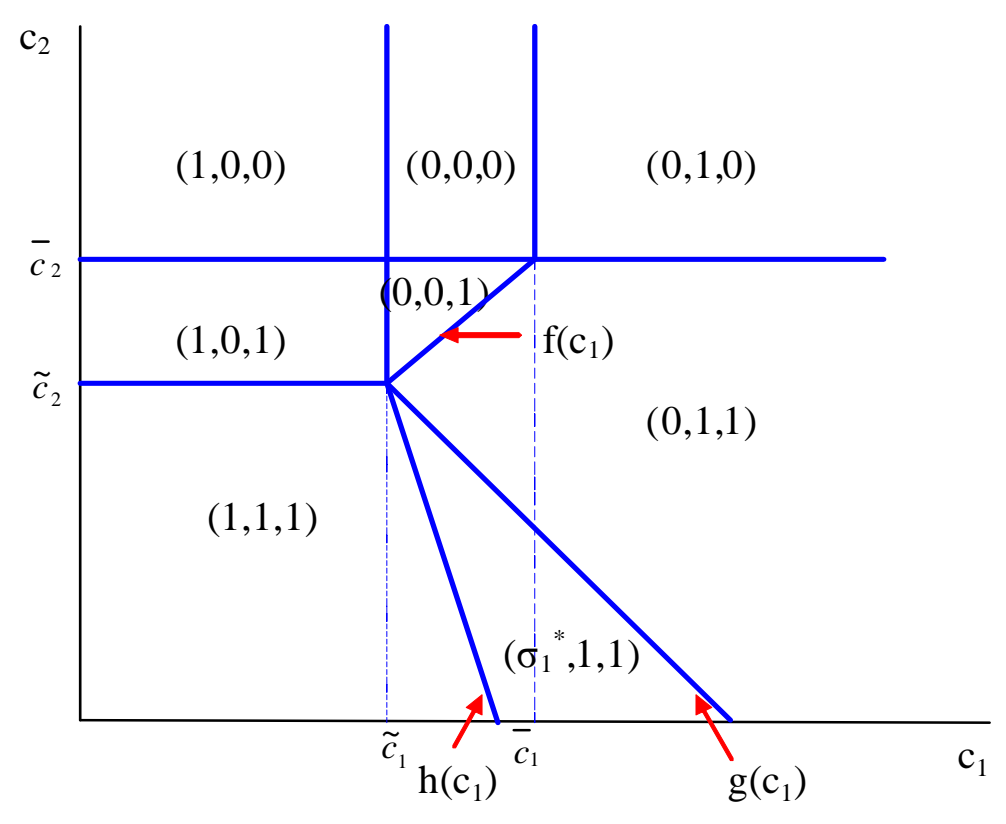

Figure 5: Equilibria with $k>0$

active equilibrium with $(1,0,1)$. In the latter case, $A_{1}$ searches, trades with $A_{3}$ and not $A_{2}$, but if $A_{2}$ acquired $x$, off the equilibrium path, he would search for $A_{3}$. It may be at least as relevant to add not only a production cost $A_{1}$, but also a production cost for $A_{2}$ before he retrades $x$, capturing the cost of improvements as when flipping real estate. The results for this case (not show) are essentially the same, but all regions in Figure 5 shift down, and in particular, the region with active middlemen region shrinks, naturally.

We now compare our predictions with those in the original RW model. One difference that does not make RW a special case of our setup is that they only recycle $A_{2}$, replacing $A_{1}$ and $A_{3}$ by clones, after each trade. We also solved our model with that assumption, and the results basically differ only in the region for $s=(1,1,1)$ now being bounded above by $f\left(c_{1}\right)$. The main result in RW is that middlemen are active if and only if they meet end users faster than originators meet end users, $\alpha_{23}>\alpha_{13}$. Setting $c_{n}=k_{n}=0$, as in RW, but still allowing general $\theta$ 's, we can show the following: when all agents are recycled, middlemen are active if and only if $\alpha_{23} \theta_{23}>0$ and $\alpha_{12} \theta_{12}>0$; and when $A_{2}$ are recycled while $A_{1}$ and $A_{3}$ are cloned, they are active if and only if $\alpha_{23} \theta_{23}>\alpha_{13} \theta_{13}$ and $\alpha_{12} \theta_{12}>0$. Interestingly, what 
matters here are the products of the $\alpha$ 's and $\theta$ 's, as emphasized in some other search models (e.g., Lagos and Rocheteau 2009). Naturally, the results also depend on who gets recycled or cloned. ${ }^{14}$

Having solved (several versions of) this model, we now revert to the baseline specification, with an arbitrary number of types $N$, but $A_{n}$ can only trade $x$ to $A_{n+1}$. The main point of this section is two fold: First, it provides a strict generalization of the standard RW model, allowing for differences in bargaining powers, search or production costs, etc. Second, it demonstrates that the economic content of the results is quite similar here and in our baseline model, as one can see by comparing Figure 4 or 5 with Figure 3. Since the economics is similar, and given the baseline version is more tractable, for what we do next, we use it in what follows.

\section{Multiple Middlemen}

In the model where $A_{n}$ can only trade $x$ to $A_{n+1}$, given that the latter plans to trade it again, the indifference condition when $A_{n}$ and $A_{n+1}$ bargain is

$$
\frac{\alpha_{n+1} y_{n+1}-c_{n+1}}{r+\alpha_{n+1}}-y_{n}=\left(1-\theta_{n}\right)\left(-\gamma_{n}+\frac{\alpha_{n+1} y_{n+1}-c_{n+1}}{r+\alpha_{n+1}} .\right)
$$

Solving for $y_{n}$, we have

$$
y_{n}=\left(1-\theta_{n}\right) \gamma_{n}+\theta_{n} \frac{\alpha_{n+1} y_{n+1}-c_{n+1}}{r+\alpha_{n+1}} \equiv \rho_{n}\left(y_{n+1}\right) .
$$

We interpret $y_{n}=\rho_{n}\left(y_{n+1}\right)$ as a best response condition for $A_{n}$ : it gives $y_{n}$, his initial offer strategy when he meets $A_{n+1}$, as a function of others' strategies, as summarized by $y_{n+1}$ which is all he needs to know when he chooses $y_{n}$.

Conditional on $A_{n}$ having acquired $x$, it is easy to see that $A_{n}$ and $A_{n+1}$ end up trading in equilibrium if and only if:

\footnotetext{
${ }^{14}$ We can compare this models and RW in terms of other predictions, e.g. we can show $y_{23}>y_{13}>y_{12}$, as in RW, with symmetric bargaining. We can also compute, as in RW, intermediaries' profit margin,

$$
y_{23}-y_{12}=r \gamma \frac{\theta_{23}\left[r+\alpha_{13} \theta_{13}+\alpha_{21}\left(1-\theta_{12}\right)+\alpha_{12} \theta_{12}(1-m)\right]+\left(1-\theta_{12}\right)\left(\alpha_{23} \theta_{23}-\alpha_{13} \theta_{13}\right)}{\left[r+\alpha_{23} \theta_{23}+\alpha_{21}\left(1-\theta_{12}\right)\right]\left(r+\alpha_{13} \theta_{13}\right)+\left(r+\alpha_{23} \theta_{23}\right) \alpha_{12} \theta_{12}(1-m)},
$$

and show it is increasing in $\alpha_{23}$ and $\theta_{23}$, and vanishes as $r \rightarrow 0$.
} 
1. $V_{n}=\frac{\alpha_{n} y_{n}-c_{n}}{r+\alpha_{n}} \geq \gamma_{n}$, so $A_{n}$ wants to search;

2. $V_{n, n+1}=y_{n} \geq \gamma_{n}$, so $A_{n}$ wants to trade;

3. $V_{n+1, n}=-y_{n}+V_{n+1} \geq 0$, so $A_{n+1}$ wants to trade.

The second condition is not binding given the first, while the third reduces to

$$
y_{n+1} \geq \frac{\gamma_{n}\left(r+\alpha_{n+1}\right)+c_{n+1}}{\alpha_{n+1}} .
$$

Now, to investigate how long intermediation chains can be, consider a quasi-stationary environment, where $\alpha_{n}, c_{n}$ and $\theta_{n}$ are the same for all $n$, while $\gamma_{n}=\gamma$ for $n \leq N, \gamma_{N+1}=\hat{\gamma}>\gamma$, and $\gamma_{n}=0$ for $n>N+1$. We call $A_{N+1}$ the end user because, if he gets $x$, he consumes it, since $A_{n}$ does not value $x$ for $n>N+1 .{ }^{15}$

Now $(23)$ can be written $y_{n}=\rho\left(y_{n+1}\right)$ for $n<N$, where $\rho(y)=(1-\theta) \gamma+\theta(\alpha y-c) /(r+\alpha)$, while $y_{N}=(1-\theta) \gamma+\theta \hat{\gamma}$. Clearly, $\rho(y)$ has a unique fixed point,

$$
y^{*}=\frac{(1-\theta) \gamma(r+\alpha)-\theta c}{r+\alpha(1-\theta)},
$$

where we assume $c<(1-\theta) \gamma(r+\alpha) / \theta$ so $y^{*}>0$. See Figure 6 , where (it is easy to check) $y_{N}>\gamma>y^{*}>\rho(0)$. The way to read in Figure 6 is: given $A_{n+1}$ correctly anticipates getting $y_{n+1}$ from $A_{n+2}$, in bargaining with $A_{n}$ the equilibrium outcome is $y_{n}$. Now, to find equilibrium, begin by working backwards: set $y_{N}=(1-\theta) \gamma+\theta \hat{\gamma}$ and iterate on $y_{n}=\rho\left(y_{n+1}\right)$ to construct a sequence $\left\{y_{n}\right\}$, where it is obvious that $y_{n} \rightarrow y^{*}$ as $n \rightarrow-\infty$. Then, since we are actually interested in what happens as $n$ increases, moving forward in real time, pick a point in this sequence and iterate forward. This generates a candidate equilibrium.

The sequence thus constructed is still only a candidate equilibrium because we still have to check if search is viable for all agents in the chain. Clearly we cannot have arbitrarily long chains, since, going backwards in time, this would involve starting arbitrarily close to $y^{*}<\gamma$, and if $y_{n}<\gamma$ the holder of $x$ would rather consume it than search. Consider, e.g., starting with $A_{N-2}$ holding $x$. Suppose $A_{N-2}$ searches and trades $x$ to $A_{N-1}$, who then searches and

\footnotetext{
${ }^{15}$ As above, we are asserting that $x$ cannot go from $A_{N+1}$ to $A_{N+2}$ when $\gamma_{n}=0$ for all $n>N+1$. This follows as a special case of the no-bubble result given below for models with linear utility.
} 


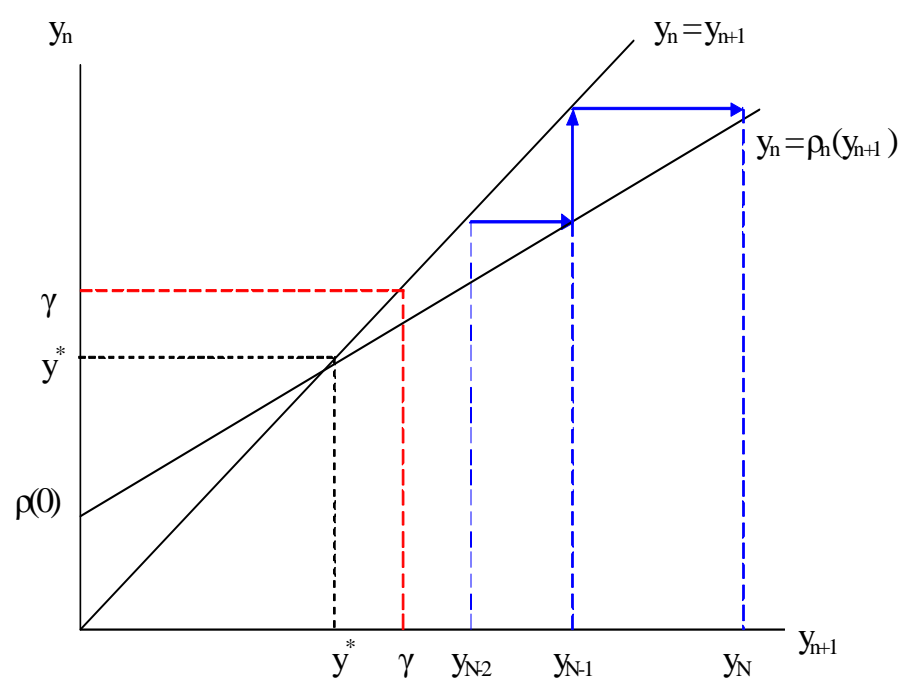

Figure 6: Path of $y_{n}$

trades with $A_{N}$, who finally searches and trades $x$ to the end user $A_{N+1}$. To see if this is viable, solve for $y_{N-2}=\rho^{2}\left(y_{N}\right)$, where $\rho^{2}(\cdot)=\rho \circ \rho(\cdot)$, and check

$$
V_{N-2}=\frac{\alpha \rho^{2}\left(y_{N}\right)-c}{r+\alpha} \geq \gamma .
$$

If $c$ is not too big, we can support trade with two middlemen between the originator and end user. For any $c>0$ we cannot support trade with an arbitrary number of middlemen: $y_{N-j} \rightarrow y^{*}<\gamma$ implies there is a maximum viable chain. However, if $\gamma=c=0$, then $y^{*}=0$ and there are arbitrarily long chains starting near 0 and ending at $y_{N}$.

Even this simple model generates some interesting predictions. To illustrate, let $T_{n}$ be the random date when $A_{n}$ trades $x$ to $A_{n+1}$. There are two striking properties of our trading process, one from economics and one from statistics. First, as is obvious from Figure 6 and reproduced in Figure 7, $\triangle y$ increases over time: as $x$ gets closer to the end user, not only $y$ but the increments in $y$ rise. Second, since the underlying arrival rates are Poisson, as is well known, the interarrival times $T_{n}-T_{n-1}$ are distributed exponentially. This entails a high probability of short, and a low probability of long, interarrival times. Hence, typical realizations of the process have trades clustered, with many exchanges occurring in short intervals separated by long intervals of inactivity. This gives the distinct appearance of 


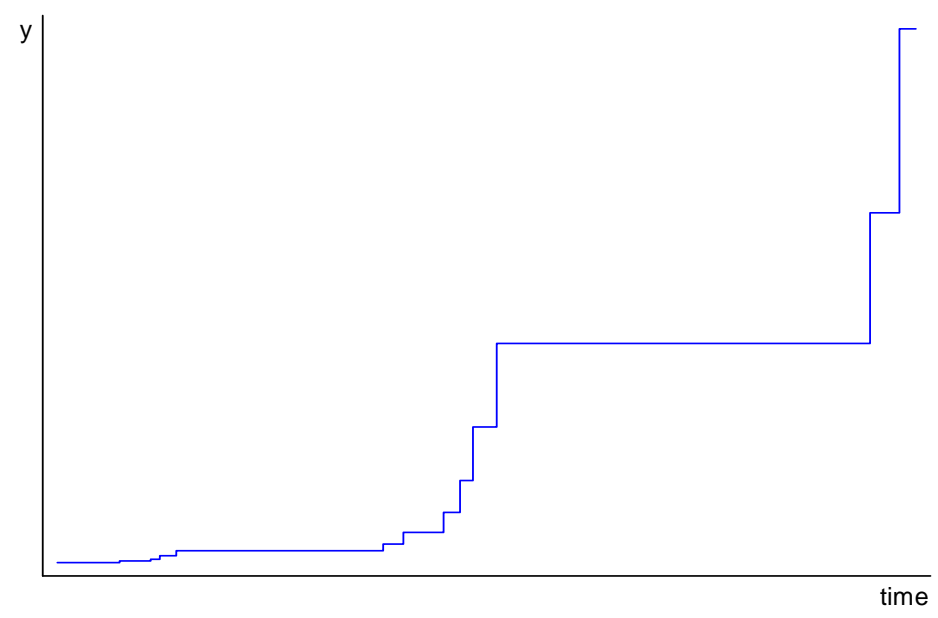

Figure 7: Typical realized path for $y$

market frenzies interspersed by long lulls, although since Poisson arrivals are memoryless there are indubitably no frenzies or lulls in any meaningful economic sense. ${ }^{16}$

Figure 7 illustrates these two features of equilibrium: the statistical property that intervals of rapid activity are interspersed by long lulls; and the economic property that $y$ grows at an increasing rate as it approaches the end user. To the naive eye this may resemble bubble-like behavior, but we cannot emphasize strongly enough that this is not a bubble. Everything in equilibrium is pinned down by the fundamental (utility) value of $x$ and by bargaining power: the terminal condition is $y_{N}=(1-\theta) \gamma+\theta \hat{\gamma}$, and from this, the stochastic trading process is given by iterating on $y_{n}=\rho\left(y_{n+1}\right)$. Does this mean bubbles are impossible? We address this in Sec. 7, after discussing some more basic issues.

\section{Discussion}

Since the Introduction, we have refrained from using the words buyer, seller and price. This is intentional, as we want to raise some issues associated with such usage. First, we contend

\footnotetext{
${ }^{16}$ This is explained in any good text on stochastic processes. As Çinlar (1975,79-80), e.g., puts it: "the interarrival times $T_{1}, T_{2}-T_{1}, T_{3}-T_{2}, \ldots$ are independent and identically distributed random variables, with the ... exponential distribution ... Note that this density is monotone decreasing. As a result, an interarrival time is more likely to have a length in $[0, s]$ than in a length in $[t, t+s]$ for any $t$. Thus, a Poisson process has more short intervals than long ones. Therefore, a plot of the time series of arrivals on a line looks, to the naive eye, as if the arrivals occur in clusters." Yet the memoryless property implies that "knowing that an interarrival time has already lasted $t$ units does not alter the probability of its lasting another $s$ units."
} 
that in the analog to our model found in much of the search literature, in our notation, $x$ represents a good and $y$ money; and on this interpretation $y$ is the price, the agent who trades $x$ for $y$ is a seller, and the one who trades $y$ for $x$ is a buyer. Noteworthy models that we view in this way, in addition to those on middlemen discussed earlier, include Diamond (1971,1987), Butters (1977), Burdett-Judd (1983) and Rubinstein-Wolinsky (1985), all of which have an indivisible object corresponding to $x$ called a consumption good (or in some applications a production good like labor), and a divisible object $y$ interpreted as the price (or wage). Of course, although they may think of $y$ as dollars, these models do not literally have money - what they have is transferrable utility. ${ }^{17}$

Identifying money with (more accurately, confusing money with) transferrable utility is standard fare by even the best economic theorists. Consider Binmore (1992): "Sometimes it is assumed that contracts can be written that specify that some utils are to be transferred from one player to another ... Alert readers will be suspicious about such transfers ... Utils are not real objects and so cannot really be transferred; only physical commodities can actually be exchanged. Transferable utility therefore only makes proper sense in special cases. The leading case is that in which both players are risk-neutral and their von Neumann and Morgenstern utility scales have been chosen so that their utility from a sum of money $x$ is simply $U(x)=x$. Transferring one util from one player to another is then just the same

\footnotetext{
${ }^{17}$ Submitted in evidence, from middlemen papers, consider the following: Rubinstein-Wolinsky (1987, p.582) describe payoffs as "consumption values (in monetary terms)." Biglaiser (1993, p.213) says "Each buyer is endowed with money." Yavas (1994) describes a standard model of middleman by "The sellers and the middlemen value the good (in monetary terms) at zero, while the buyers value the good at one." Yavas (1992) is more careful, saying "In order to avoid the additional questions associated with having money in the economy, this endowment has not been labeled as money." Johri-Leach (2002) are also careful to say "units of a divisible numeraire good are exchanged for units of an indivisible heterogeneous good," although they have no problem assuming payoffs are linear in the former. Even those less cavalier about money are quick to deem who is a buyer or seller and what is the price.

In search theory outside the middleman literature, Butters (1977, p.466) says "A single homogeneous good is being traded for money," while Burdett-Judd (1983, pp.955,960) say consumers search "to lower the expected costs of acquiring, a desired commodity, balancing the monetary cost of search against its monetary benefit," while firms want to "make more money." Diamond $(1971,1987)$ does not mention money explicitly, but he thinks of $y$ as the price, and buyers are those with payoff $\gamma-y$ while sellers are those with payoff $y$. In several places Osborne-Rubinstein (1990) decribe models where "A single indivisible good is traded for some quantity of a divisible good ('money')." Gale (1987, p.20) more accurately says "A single, indivisible commodity is traded. Buyers and sellers have transferable utility." To sum up, with some exceptions, this literature suggests we interpret $x$ as a good, $y$ as a money price, $A_{n}$ as a seller and $A_{n+1}$ as a buyer.
} 
as transferring one dollar." Unfortunately, it ain't necessarily so - and this is about more than an abhorrence for the dubious, if evidently not discredited, practice of putting money in the utility function.

In serious monetary theory, it is not trivial to transfer dollars across agents, because they tend to run out. No one has an unlimited supply of cash in hand, and for almost all inflation rates, other than the Friedman rule, agents carry less than the amount required for unconstrained trade. And, in any case, payoffs are usually not linear in dollars, with some exceptions, such as models following Lagos-Wright (2005); even there, however, buyers typically end up running out of money, which makes it very different from transferrable utility. Examples of search-based monetary theory that look like the setup in this paper include the models in Shi (1995), Trejos-Wright (1995), Kocherlakota (1998), Wallace (2001) and many others. The point we emphasize is that all those models take a diametric position to the above-mentioned applications outside of monetary economics: they assume $y$ is a consumption good and $x$ is money.

An obvious difference across these interpretations is that, under one, money $(y)$ is divisible and the consumption good $(x)$ is indivisible, while under the other, money $(x)$ is indivisible and good $(y)$ is indivisible. Superficially this favors the first view, as divisibility is a property (along with storability, portability etc.) commonly associated with money, but on reflection we do think this should be given much weight, since we could easily make $x$ and $y$ divisible. Better discriminating criteria stem from the functional definitions of money: it is a unit of account, store of value and medium of exchange. The unit of account function, which means American prices tend to be quoted in dollars and European prices in euros, seems uninteresting, since for anything of consequence it cannot matter much whether we measure prices in dollars or euros any more than whether we measure distance in feet or meters. Regarding the store of value function, it is clear in the model that it is $x$ and not $y$ playing that role: $x$ is a durable good that, when acquired by $A_{n}$ enables him to enjoy a payoff $y_{n}$ at a future date. The more natural interpretation of $y$ is that it is a perishable good, or a service, produced for immediate consumption, and it is hard to imagine that as money. 
By contrast, $x$, which is kept in inventory, is obviously a storable asset and satisfies the standard definition of a medium of exchange: an object that is accepted in trade not to be consumed or used in production by those who accept it, but instead to be traded again later. Now, in the above model $x$ happens to be commodity money, since an end user ultimately does consume it for a direct payoff, as opposed to fiat money which does not generate a direct payoff for anyone. But $y$ is certainly not a medium of exchange in the above models: it is accepted by everyone for its direct payoff, and never to be traded again later. Moreover, it is exactly a double-coincidence problem that makes $x$ useful: when $A_{n}$ wants $y$ from $A_{n+1}$, he has nothing to offer except asset $x$. One could also argue $x$ plays much the same role that money plays in non-search monetary theory, such as overlapping-generations models (Wallace 1980), although we do not have space to go into this here. Based on all this, in terms of calling either $x$ or $y$ money, readers can decide for themselves, but it looks to us like the monetary theorists got this one right.

Does it matter? While at some level one might say the issue is purely semantic, as if that were reason not to be interested, we think it actually may matter substantively for how one uses the theory. For instance, it determines who we call the buyer or seller and what we mean by the price. To make this point, we first argue that in nonmonetary exchange say, when $A$ gives $B$ apples for bananas - it is not meaningful to call either agent a buyer or seller. Of course, one can call them whatever one likes, but then the labels buyer and seller convey nothing more than calling them $A$ and $B$. However, when $A$ gives $B$ apples for genuine money, for dollars or euros, everyone should agree that $A$ is the seller and $B$ the buyer (it is perhaps less clear what to call them when $A$ gives $B$ euros for dollars, but that is beside the point). We identify agents who pay money as buyers and ones who receive money as sellers, and claim this corresponds to standard usage. ${ }^{18}$

\footnotetext{
${ }^{18}$ As evidence, consider the following definitions of the verbs buy and sell: "acquisition of an article, and legal assumption of its ownership, in exchange for money or value" and "to transfer ownership of a property in exchange for money or value" (businessdictionary.com); "to aquire possession, ownership, or rights to the use or services of by payment especially of money" and "to give up (property) for something of value (as money)" (Meriam Webster); "to acquire the possession of, or the right to, by paying or promising to pay an equivalent, esp. in money" and "to transfer (goods) to or render (services) for another in exchange for money" (Dictionary.com); or "to get something by paying money for it" and "to give something to someone else in return for money" (Cambridge Dictionaries Online).
} 
Again, one can label objects anything one likes, and be on firm ground logically, if not aesthetically. But would anyone want to reverse the labels in, say, the Mortensen-Pissarides (1994) labor-market model, taking the agents we usually think of as workers and calling them firms, and vice versa? One could prove the same theorems, but it would make a difference when considering applied questions (e.g., should we tax/subsidize search by workers or by firms?). Using the interpretation in the previous middlemen literature, where $y$ is money and $x$ is a good, when $A_{n}$ and $A_{n+1}$ trade the former is the seller and the latter is the buyer. Using the interpretation in the monetary literature mentioned above, where $x$ is money and $y$ is a good, $A_{n}$ is the buyer and $A_{n+1}$ is the seller. If one agrees that it makes a substantive difference who we call workers and firms in the labor market, it can similarly make a difference who we call buyers and sellers in goods markets (e.g., for substantive questions, like should we tax/subsidize shoppers or retailers?).

Moreover, the two interpretations give opposite predictions for price behavior. If we normalize the size of the indivisible $x$ to 1 , without loss of generality, under the interpretation that $y$ is money and $x$ is a good, the price is obviously $y$. But if $y$ is the good and $x$ is money then $1 / y$ is the price, since now a normalized unit of money buys $y$ units of the good. To see how this matters, look back at Figure 7. Using the first interpretation, theory predicts prices are rising over time, as more and more money $y$ is required to buy the same amount of consumption $x$ as we get closer to the end user. Using the second interpretation, prices are falling, as over time more and more consumption $y$ can be acquired for the same amount of money $x$. For empirical work, at least, one has to make a choice. We do not propose one irreproachable interpretation, since this depends on the issues at hand. We do think it is relevant to broach the issue.

We also find it intriguing that, from a legal standpoint, it often makes a vital difference who we construe as buyer and seller. It is not uncommon to have laws or conventions that allow buyers to return goods and demand a refund, or at least store credit, within a certain period of time with no questions asked - the principle of caveat emptor notwithstanding. ${ }^{19}$

\footnotetext{
19 "The two basic types of warranties are express warranties and implied warranties. An express warranty is any representation or affirmation about the goods made by the seller's words or conduct. ... Implied
} 
We are not aware of similar laws or conventions applying to sellers, and, with rare exceptions like bad checks or counterfeit currency, accepting monetary payment entails finality suggesting a more rigorous principle of caveat venditor. Also, in law, "There is a 'bias' in favour of buyers. Buyers are not obligated to disclose what they know about the value of a seller's property, but sellers are under a qualified obligation to disclose material facts about their own property." (Ramsay 2006). Beyond legal systems narrowly construed, is also true that private trading platforms, like ebay, have rules and regulations that treat buyers and sellers differently (see, e.g., Beal 2009).

We also cannot help but comment on the asymmetric treatment of buyers and sellers in illegal markets. It is commonly understood that with drugs and prostitution, the one who receives the money is usually treated much more harshly than the one who pays (which raises a question about trading drugs directly for sex, but like trading dollars for euros, this is beside the point). Indeed, with drugs, it is so much more common to target sellers than buyers that targeting the latter is referred to as a "reverse sting" operation. With prostitution, buyers have almost always been treated much more leniently than sellers. ${ }^{20}$ Similarly, sellers are typically the bigger villains where illegal gambling, booze, guns, fireworks etc are concerned. Although we are less sure about it, we conjecture this is also true for stolen merchandise. And note, by the way, that a fence is a middleman in our model. Intermediaries in general and fences in particular are often considered less than honorable, if not outright heinous, perhaps because they do not themselves produce anything and simply profit from others, as evidenced by our epigraph referring to "bloodsucking bastards" and by other timeless

warranties are warranties that are imposed on sellers by law. A warranty of merchantability is implied in every sales contract. This warranty is a promise that the goods pass without objection in the trade, are adequately packaged, conform to all promises or affirmations of fact on the container, and are fit for the ordinary purposes for which such goods are used. The implied warranty of merchantability also includes a promise that multiple goods will be of even kind and quality." From "Sales Law - Warranties" at http://law.jrank.org/pages/9989/Sales-Law-Warranties.html.

${ }^{20} \mathrm{An}$ obvious exception is when politicians get caught with prostitutes, but in general, the point is valid. See the "The Staight Dope" at http://www.straightdope.com/columns/read/2774/prostitution. Of course, some argue that this is merely another manifestation of male dominance: "As long as society remains male dominated, women selling sex will be in a more vulnerable position than men buying sex." See "The swedish approach to prostitution" at http://www.sos-sexisme.org/English/swedish.htm. This suggest an obvious empirical test by looking at male prostitutes if one were willing to swallow some rather dubious ceterus paribus assumptions. 
condemnations of moneylenders and the like. This, of course, at least in part comes from ignorance of the idea that getting goods from $A$ to $B$ is a productive activity.

In any case, for what it's worth, we find it interesting that it is the norm to deem sellers - those who receive money in exchange for goods - worse in legal and moral senses than buyers - those who receive goods in exchange for money. There are exceptions, as in the case of in child prostitution, but this can be explained by saying that the distinction between adults and minors takes precedence over the distinction between buyers and sellers without denying the existence of the latter. Another exception might be when a student, or, perish the thought, a professor, gives someone money to write a paper for them. ${ }^{21}$

Returning to the theory, consider again Figure 1. The usual approach to middlemen interprets $x$ as a consumption good being passed from originator to end user by chains of intermediaries. At each link in the chain $x$ trades for $y_{n}$ units of money - or, better, for $y_{n}$ transferable utils - or, better still, for some amount of a different consumption good that is produced at cost $y_{n}$ by $A_{n+1}$ and consumed for utility $y_{n}$ by $A_{n}$. We have no problem with linear utility, our quibble is more about asserting that agents getting direct utility from money, or if it is interpreted as indirect utility, that the value function is linear in dollars. These issues aside, we think our framework provides a useful model of intermediation chains, where one good $x$ trades for another good $y$, or even a sequence of different goods $\left\{y_{n}\right\}$, since it is easy to imagine $A_{n}$ altering or improving $x$ in some way before he flips it to $A_{n+1}$. But it is also a coherent model of agents trading an asset $x$ in exchange for goods produced at cost $y_{n}$ by $A_{n+1}$ and consumed for utility $y_{n}$ by $A_{n}$.

Also notice that if we use modulo $N$ arithmetic, our chain becomes a circle, where $A_{1}$

\footnotetext{
${ }^{21}$ Our objective is to point out asymmetries between buyers and sellers, not to explain them, but there are various rationales. On focusing enforcement on drug or gun dealers rather than buyers, it is sometimes said there are barriers to entry, at least at the high end, so that it is difficult for newcomers to replace those who are incarcerated (Koper and Reuter 1995). Yet the reverse argument can be made at the low end, where a dealer removed from a streetcorner is quickly replaced. Other arguments include the view that those who profit most from illegal activity should face highest risk of punishment, as should those that provide bad role models by their financial success. Another is the principle that we ethically judge actions that put others at risk more harshly than those that put oneself at risk; while this might ring true for drugs, it is difficult to make the case for prostitutes. The same might be said for the position that if $B$ is weak and $A$ exploits that weakness, $A$ should be judged more harshly. There is also the idea that for many markets, legal or illegal, sellers have a lot more transactions than buyers, so it is cost effective to go after sellers. We leave exploration of these ideas to future research.
} 
consumes the output of $A_{2}$ who consumes the output ... of $A_{N}$ who consumes the output of $A_{1}$. This looks like the environment used to study money in Kiyotaki and Wright (1989), or the generalization in Aiyagari and Wallace (1991). Hence, one might wonder, could the model support equilibria where $x$, like some commodity money, is never consumed?

\section{Intermediation Bubbles}

This leads us to a discussion of bubbles. ${ }^{22}$ In the analysis so far, we could get chains of trade, and with $c_{n} \approx 0$ these chains can be quite long, but the equilibrium is always tied down by the fact that there is a determinate end user who consumes $x$. Now consider the possibility that no one consumes $x$, and it gets passed around forever. For this exercise, assume a stationary environment: $\alpha_{n}=\alpha, c_{n}=c, \theta_{n}=\theta$ and $\gamma_{n}=\gamma$ for all $n$. The best response function is

$$
y_{n}=(1-\theta) \gamma+\theta \frac{\alpha y_{n+1}-c}{r+\alpha}=\rho\left(y_{n+1}\right),
$$

shown in Figure 8. The viability condition for $A_{n}$ to search is $\gamma \leq\left(\alpha y_{n+1}-c\right) /(r+\alpha)$.

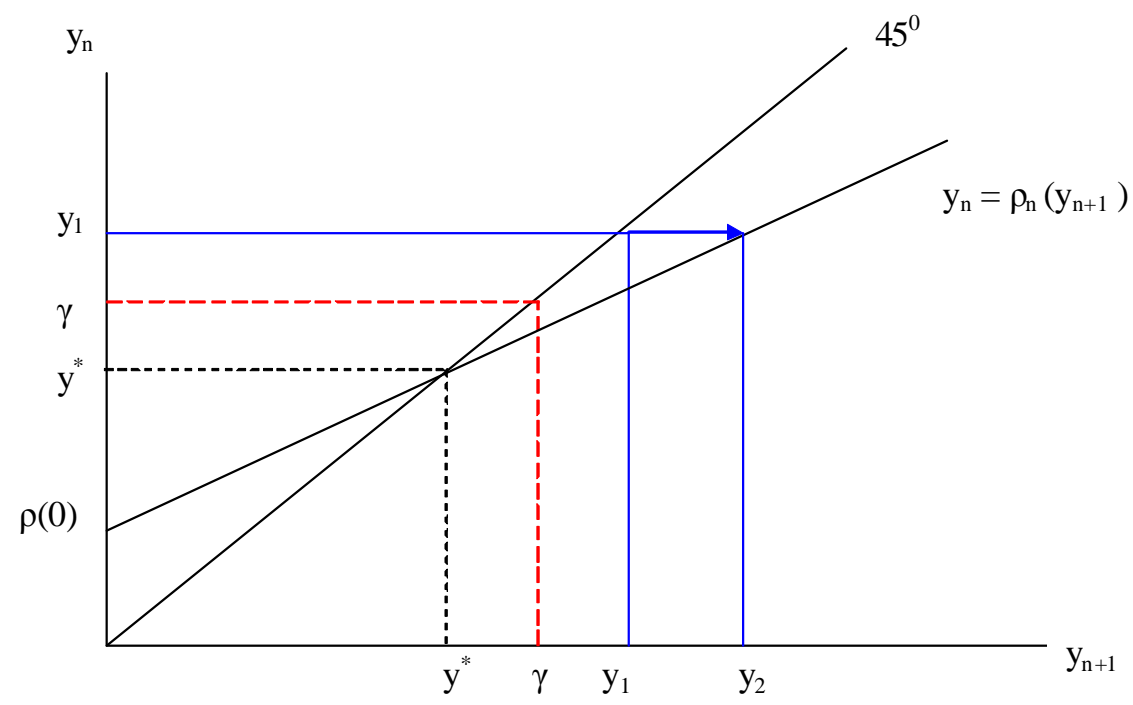

Figure 8: Best-response condition (with linear utility)

\footnotetext{
${ }^{22}$ We will define what we mean by this term presently. The bubble literature is ever expanding, to the extent that it is too big to go into here; recent papers by Farhi and Tirole (2010) and Rocheteau and Wright (2010) provide extensive references and help put our results in context.
} 
The principal difference from the quasi-stationary model, with a manifest end user $A_{N+1}$, is that we no longer have a terminal condition $y_{N}=\theta \gamma+(1-\theta) \hat{\gamma}$ to tie down the equilibrium path. Still, since $y_{n}=\rho\left(y_{n+1}\right)$ implies $\partial y_{n+1} / \partial y_{n}=(r+\alpha) / \alpha \theta$, as seen in Figure 8, there is only one solution to the difference equation (25) that remains nonnegative and bounded: $y_{n}=y^{*}$ for all $n$. Any path that starts at $y>y^{*}$ looks like a bubble: agent $A_{n}$ is willing to search for $A_{n+1}$ because he expects a high $y_{n}, A_{n+1}$ is willing to give a high $y_{n}$ because he expects an even higher $y_{n+1}$, etc. But such explosive paths are not consistent with equilibrium when we make the standard assumption that there is an upper bound on $y$, say $\bar{y}$ (e.g., $\bar{y}$ could be total output of known universe). One cannot rationally believe that $y_{n}$ will grow beyond $\bar{y}$, and hence an explosive bubble-like sequence $y_{n}$ cannot be an equilibrium. The only equilibrium is $y_{n}=y^{*}$ for all $n$, and $\gamma>y^{*}$ implies $V_{n}=\left(\alpha y^{*}-c\right) /(r+\alpha)<\gamma$. Since $V_{n}<\gamma$, in equilibrium, no one searches.

These results seem quite natural. How could there be no gains from trade when all agents have the same $\gamma$ ? Hence, there is no trade on the equilibrium path. If $A_{n}$ were to trade $x$ to $A_{n+1}$, off the equilibrium path, he must get exactly $y_{n}=\gamma$ for it, since he couldn't get more and he wouldn't take less. We call $y_{n}=\gamma$ the fundamental value of $x$, which is evidently what it is worth in terms of intrinsic properties. In the above environment, there are no gains from trade based on fundamentals. We would say that a bubble exists in this situation when, in equilibrium, $A_{n}$ and $A_{n+1}$ trade and this generates a positive surplus. The above discussion implies that in this environment there cannot be bubbles in equilibrium. ${ }^{23}$

We now change the model slightly, by letting the utility of consuming $y$ be $U(y)$, with $U(0)=0, U^{\prime}>0$ and $U^{\prime \prime}<0$ (keeping the cost of producing $y$ equal to $y$ ). Then $y_{\gamma}=U^{-1}(\gamma)$ becomes the cost to $A_{n+1}$ of covering $A_{n}$ 's outside option $\gamma$, and our usual bargaining game leads to

$$
y_{n}=(1-\theta) y_{\gamma}+\theta \frac{\alpha U\left(y_{n+1}\right)-c}{r+\alpha}=\rho\left(y_{n+1}\right)
$$

in a stationary environment. Figure 9 shows a case where $y^{*}>y_{\gamma}$, or equivalently, $U\left(y^{*}\right)>\gamma$,

\footnotetext{
${ }^{23}$ This version of a standard no-bubble result confirms as a special case our ealier assertion that if $A_{N+1}$ gets $x$ he will consume it in the quasi-stationary model with $\gamma_{n}=0$ for $n>N+1$.
} 


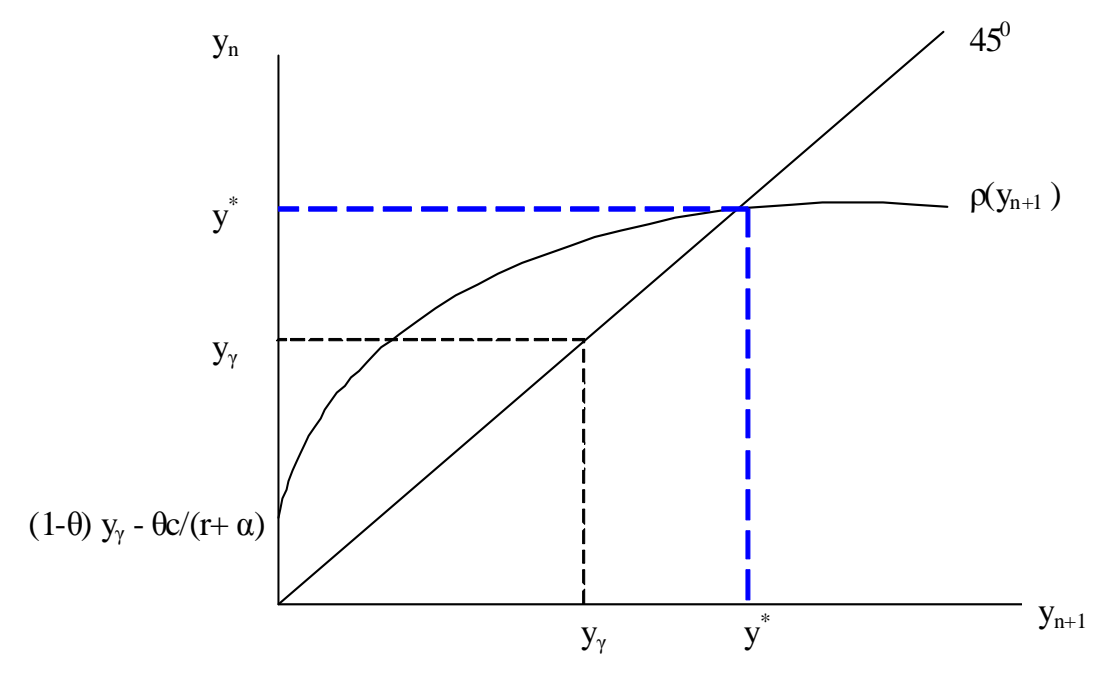

Figure 9: Best-response condition (with nonlinear utility)

which we could not get in the linear case $U(y)=y \cdot{ }^{24}$ Since $U\left(y^{*}\right)>\gamma$ is necessary to satisfy the search viability condition $\gamma \leq\left[r U\left(y^{*}\right)-c\right] /(r+\alpha)$, we at least have a chance, which we did not have with $U(y)=y$.

We now show by way of example that search and trade can be viable in equilibrium. Suppose $U(y)=\sqrt{y}$, which means $y_{\gamma}=\gamma^{2}$. Setting $c=0$, for now, the key difference equation becomes

$$
\rho(y)=(1-\theta) \gamma^{2}+\frac{\theta \alpha}{r+\alpha} \sqrt{y}
$$

To find the steady state, rewrite $y=\rho(y)$ in terms of $U=\sqrt{y}$,

$$
U^{2}-\frac{\theta \alpha}{r+\alpha} U-(1-\theta) \gamma^{2}=0
$$

Solving this quadratic for its positive root, and inserting it into the search viability condition $\gamma \leq U \alpha /(r+\alpha)$, we get

$$
\gamma \leq \frac{\theta \alpha^{2}}{r^{2}+2 r \alpha+\theta \alpha^{2}}=\bar{\gamma}
$$

Since $\bar{\gamma}>0$, search is viable for some $\gamma>0$.

Summarizing, for some $\gamma<\bar{\gamma}$ and $c=0$, we have constructed equilibrium where every $A_{n}$ searches, and trades $x$ to $A_{n+1}$ for $y_{n}=y^{*}$, with no one ever consuming $x$. In such an

\footnotetext{
${ }^{24}$ As drawn, Figure 9 shows the existence of a unique positive solution to $y^{*}=\rho\left(y^{*}\right)$, which is true iff $0<\rho(0)=(1-\theta) y_{\gamma}-\theta c /(r+\alpha)$, which holds as long as $c$ or $\theta$ is small or $\alpha$ is big.
} 
equilibrium, $x$ circulates forever. For this to be viable we require $\left[\alpha U\left(y^{*}\right)-c\right] /(r+\alpha) \geq \gamma$, and a fortiori $y^{*}>y_{\gamma}$. The amount of $y$ required to acquire $x$ is above the fundamental value and the surplus from trade between $A_{n}$ and $A_{n+1}$ is $S^{*}=U\left(y^{*}\right)-y^{*}>0$, so by our definition this a genuine bubble. Once this is understood it should be clear that, by continuity, we can engineer similar bubbles when $c>0$, or $\gamma_{n}$ varies across agents, or $\gamma_{n}=0$ for all $n$, or even $\gamma_{n}<0$ for all $n$. All of these outcomes would appear anomalous in other contexts. Of course, these results rely on "the economics of infinity" (Shell 1971), but in no way are they fantastic or strange.

Can there be nonstationary bubbles? When $\rho(0)>0$, Figure 9 suggests not. With $\rho(0)>0$, all paths satisfying (26), other than $y_{n}=y^{*}$ for all $n$, either lead to $y_{n}<0$ or $y_{n}>\bar{y}$. But suppose $\rho(0)<0$, as in Figure 10, which occurs whenever $c>y_{\gamma}(r+\alpha)(1-$ $\theta) / \theta$. As long as $c$ is not too big, there are multiple steady states, $y_{1}^{*}$ and $y_{2}^{*}$. Supposing $\alpha\left[U\left(y_{1}^{*}\right)-c\right] /(r+\alpha)>\gamma$, so that search is viable when $y_{n}$ is near $y_{1}^{*}$, then as shown there are nonconstant paths for $y_{n}$ satisfying all the equilibrium conditions, even though fundamentals are stationary. Starting to the left of $y^{*}, y_{n}$ rises over time in progressively smaller increments, until settling at $y_{1}^{*}$; starting from the right, $y_{n}$ falls in progressively smaller increments until settling at $y_{1}^{*}$. Whether one says prices are rising or falling depends on where one starts, as well as whether one takes $x$ or $y$ to be money, as discussed in the previous section. In any case, the outcomes are all quite bubbly.

Although these results may not be too surprising to a monetary theorist, was it well known that standard off-the-shelf models of intermediation like RW admit equilibria with interesting dynamics once we introduce nonlinear utility? We doubt it. At least, we could not find it in the middleman literature. Now, nonlinearity is crucial here because it allows agents with perfect foresight to engage in what looks like "buying high and selling low." Consider starting to the right of $y_{1}^{*}$ in Figure 10, where in equilibrium $A_{n+1}$ gives up $y_{n}$ to get $x$, and later gives up $x$ to get $y_{n+1}<y_{n}$. This is ostensibly strange behavior for a middleman, even without taking his time and other search costs into consideration. But it is actually a good deal, since $U\left(y_{n+1}\right)$ exceeds $y_{n}$ by enough of a margin, even if $y_{n+1}<y_{n}$. 


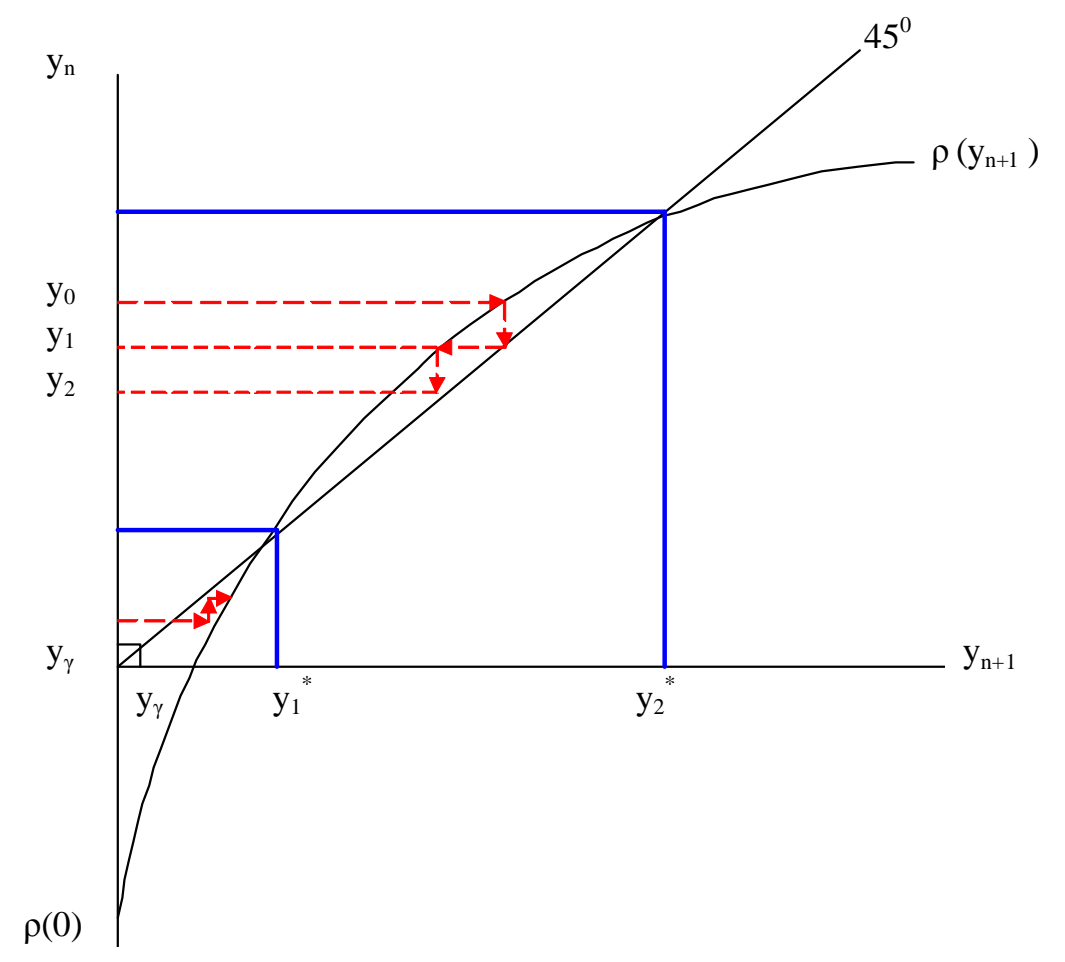

Figure 10: Best-response condition (with nonlinear utilityand $c>0$ )

Obviously this requires nonlinear utility. But now that we have let the nonlinear cat out of the bag, it seems like a good time to revisit our bargaining solution.

First, it is important to understand that it is not necessary to use our particular extensive form game to generate interesting dynamics. Consider instead generalized Nash:

$$
y_{n}=\arg \max _{y}[U(y)-\gamma]^{\theta}\left(V_{n+1}-y\right)^{1-\theta}
$$

The FOC is $\theta\left(V_{n+1}-y_{n}\right) U^{\prime}(y)=(1-\theta)\left[U\left(y_{n}\right)-\gamma\right]$, with the solution $y_{n}=\hat{y}\left(V_{n+1}\right)$, say. Inserting $V_{n+1}$ we get a dynamical system $y_{n}=\hat{\rho}\left(y_{n+1}\right)$ that is qualitatively similar to, but not the same as, the system $y_{n}=\rho\left(y_{n+1}\right)$ derived from our game. The same is true for Kalai's proportional solution,

$$
\theta\left(V_{n+1}-y\right)=(1-\theta)[U(y)-\gamma]
$$

which yields yet another dynamical system, $y_{n}=\tilde{\rho}\left(y_{n+1}\right)$. These three systems, $\rho, \hat{\rho}$ and $\tilde{\rho}$, all generate similar outcomes, including multiple stationary equilibria, and equilibria where $y_{n}$ varies with $n$ even though fundamentals are constant. 
We like our bargaining solution because it has explicit strategic foundations, something Nash himself argued was important for bargaining theory in general. ${ }^{25}$ This is often said to also be a nice property of Nash bargaining: the ideas is that one can write down a standard infinite-horizon strategic bargaining model, with randomly or deterministically alternating offers, take the limit as the time between offers goes to 0 , and out jumps the Nash solution, at least in stationary situations (Binmore 1987; Binmore, Rubinstein and Wolinsky 1986). As demonstrated in Coles and Wright (1998) and Coles and Muthoo (2003), however, this breaks down in nonstationary situations unless one makes additional assumptions, like imposing linear utility or giving one agent all the bargaining power. In general, in a nonstationary bargaining situation, when one writes down exactly the same strategic bargaining model and takes exactly the same limit, one gets a dynamical system for the terms of trade that coincides with Nash in steady state but not out of steady state unless, in our notation,one assumes that $U(y)=y$ or $\theta=1$.

The above-mentioned papers also that, unless $U(y)=y$ or $\theta=1$, using Nash out of steady state is tantamount to using the alternating-offer game where the players have $m y$ opic expectations (they believe continuation values are constant over time even though in equilibrium they are not). To the extent that one wants strategic foundations for bargaining, and wants to analyze dynamics, and to use nonlinear utility, this is a serious issue. Following Nash, we want strategic foundations, and we want to analyze nonstationary equilibria since this is an important aspect of bubble-like phenomena, and to use nonlinear utility, because as we proved this is necessary to get bubbles in the first place. Hence, we like the game used here. Having said this, for the record, and to show there is nothing especially funny about this game, we now compare the outcome to Nash and Kalai bargaining when $U(y)=\sqrt{y}$ (remember that with linear $U$ they are all the same).

In Appendix B we show the following: for each bargaining solution there is an upper bound for $\gamma$ that makes search viable; in the limit when $r \rightarrow 0$ the bounds all go to 1 ; and

\footnotetext{
${ }^{25}$ The endeavor to write down explicit economic environments where axiomatic bargaining outcomes emerge as an equilibrium is now commonly referred to as the Nash program (see, e.g., Osborne and Rubinstein 1990, Chapter 4).
} 
the the limiting steady state payoffs are

$$
\begin{aligned}
U_{s}^{*} & =\frac{1}{2}\left[\theta+\sqrt{\theta^{2}+4(1-\theta) \gamma^{2}}\right] \\
U_{n}^{*} & =\frac{1}{2-\theta}[2 \gamma(1-\theta)+\theta] \\
U_{k}^{*} & =\frac{1}{2 \theta}[2 \theta-1+\sqrt{1-4 \theta(1-\gamma)(1-\theta)}],
\end{aligned}
$$

where the subscripts $s, n$ and $k$ refer to strategic, Nash and Kalai. ${ }^{26}$ We are interested in comparing $U^{*}$, or equivalently, $y^{*}$. One can show $y_{n}^{*}<y_{s}^{*}<1$ for $\theta<1$ and $y_{n}^{*}=y_{s}^{*}=1$ for $\theta=1$, but the relationship with $y_{k}^{*}$ is less clear. The graphs below show $y^{*}$ as a function of $\theta$ for two examples with different $\gamma$, illustrating how the solutions are different, but display similar qualitative properties.

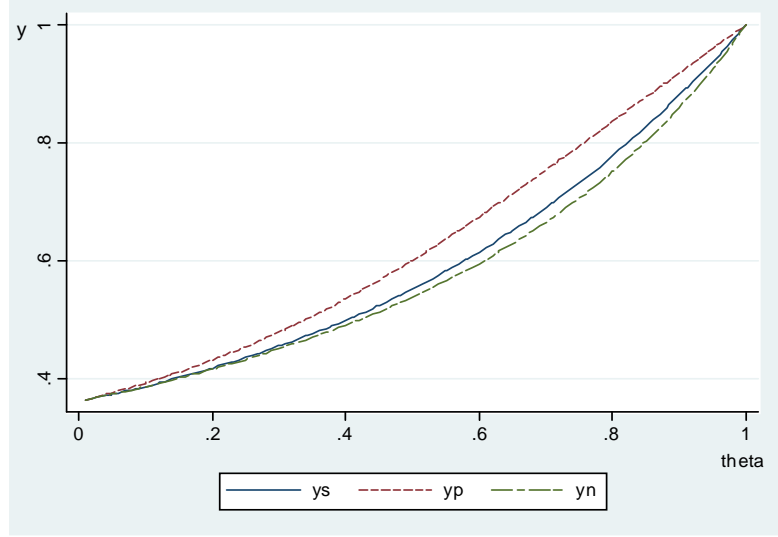

Model comparison when $\gamma=0.6$

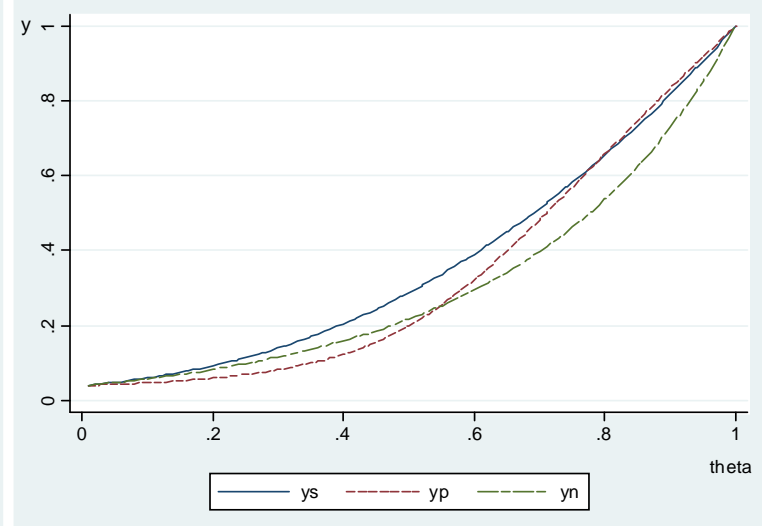

Model comparison when $\gamma=0.2$

We conclude that, even when we look only at steady states, the different bargaining solutions generally give different answers with nonlinear utility. Again, we like our solution because it has a simple strategic foundation, in and out of steady state, we want to look out of steady state because we are interested in nonstationary bubbles, and we need nonlinear utility to get bubbles. That is why we used this bargaining solution, but other solutions can also generate interesting dynamics in our model of intermediated trade.

\footnotetext{
${ }^{26}$ When $c=0$ the bounds on $\gamma$ are:

$$
\bar{\gamma}_{s}=\frac{\theta \alpha^{2}}{r^{2}+2 r \alpha+\theta \alpha^{2}}, \bar{\gamma}_{n}=\frac{\theta \alpha^{2}}{r^{2}(2-\theta)+2 r \alpha+\theta \alpha^{2}}, \bar{\gamma}_{p}=\frac{\alpha[\theta \alpha-r(1-\theta)]}{\theta(r+\alpha)^{2}}
$$

One can show $\bar{\gamma}_{n} \leq \bar{\gamma}_{s}<1$ and $\bar{\gamma}_{k}<1$, and the relationship between $\bar{\gamma}_{k}$ and the others is unclear, in general; if $\theta=1$, the bounds all collapse to $\alpha^{2} /(r+\alpha)^{2}$.
} 


\section{Conclusion}

We studied trade intermediated by middlemen, and potentially chains of middlemen. We presented a model of this activity and a discussion of various economic issues. This included a comparison of buyers vs sellers, and goods vs money vs transferrable utility, that emerged from our reading of two distinct branches of search theory, one on middlemen and one on money. It is not surprising the models in these literatures are related, given middlemen and money both exist to facilitate the process of exchange; it is perhaps surprising there is so little connection between the literatures. We think our analysis helps clarify the similarities and differences between existing theories, which is, after all, something scientists are supposed to do. We also raised some new issues, by analyzing the possible length of intermediation chains, by pursuing the notion of bargaining with bargainers and the implied holdup problems, by comparing different bargaining solutions in and out of steady state, and by explicitly constructing equilibria with bubbles. We also think these models can be applied to many substantive topics in finance, real estate and other areas, but we leave this to future research. 


\section{Appendix A}

Consider a mixed-strategy equilibrium where $\sigma_{1} \in(0,1)$ and $V_{1}=0$. For convenience, define $n=1-m$. Then write the steady state condition (14) as $\sigma_{1}=\sigma(n)$ and write $V_{1}=0$ as $\sigma_{1}=\Sigma(n)$, where

$$
\begin{aligned}
\sigma_{1} & =\sigma(n)=\frac{\pi_{2} \alpha_{23}(1-n)}{\pi_{1} \alpha_{12} n} \\
\sigma_{1} & =\Sigma(n)=\frac{\alpha_{12} \theta_{12} n\left(\bar{c}_{2}-c_{2}\right)-\left(r+\alpha_{23}\right)\left(c_{1}-\bar{c}_{1}\right)}{\alpha_{21}\left(1-\theta_{12}\right)\left(c_{1}-\bar{c}_{1}\right)} .
\end{aligned}
$$

When $\sigma_{1}=1$ (29) implies $n=n_{1}=\pi_{2} \alpha_{23} /\left(\pi_{2} \alpha_{23}+\pi_{1} \alpha_{12}\right)$. As long as $\Sigma(1)>0$ and $\Sigma\left(n_{1}\right)<1$, there exists a unique $\left(n^{*}, \sigma^{*}\right) \in\left(n_{1}, 1\right) \times(0,1)$ such that $\sigma\left(n^{*}\right)=\Sigma\left(n^{*}\right)=\sigma^{*}$. We claim that $\Sigma(1)>0$ if and only if $g\left(c_{1}\right) \geq c_{2}$ and $\Sigma\left(n_{1}\right)<1$ if and only if $h\left(c_{1}\right) \leq c_{2}$ at $n=n_{1}$. See Figure 11. The best response conditions for $\mu=1$ and $\sigma_{2}=1$ are not binding in this case. This completes the argument.

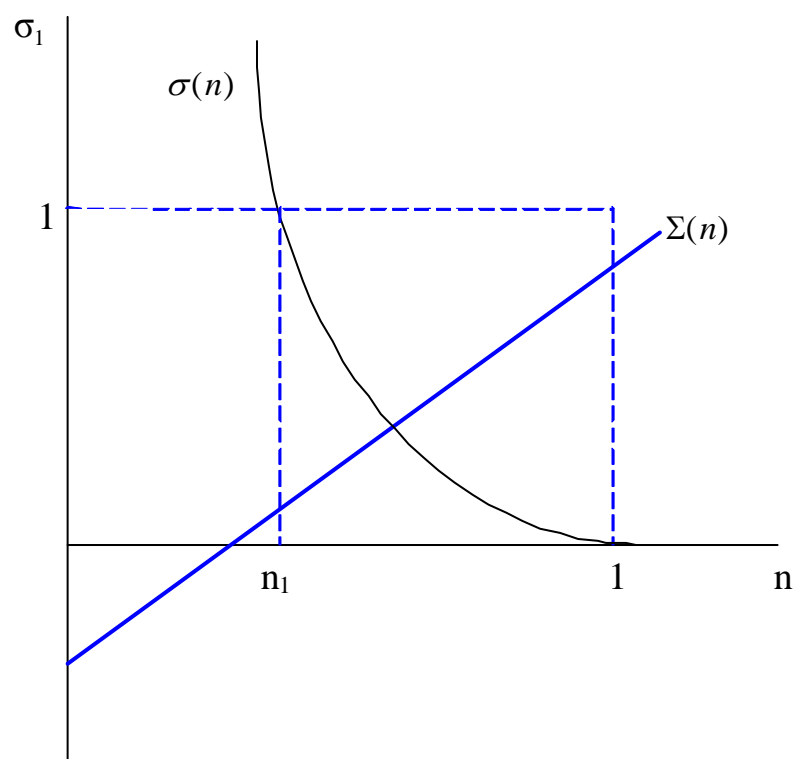

Figure 11: Existence of $\left(n^{*}, \sigma^{*}\right)$

\section{Appendix B}

Here we give some more details concerning the example with $U(y)=\sqrt{y}$. First, we can extend the case of our bargaining solution by relaxing the assumption $c=0$ made in the 
text. One can show search is viable if and only if $Q(\gamma) \geq 0$, where $Q(\cdot)$ is the quadratic

$$
Q(\gamma)=-\gamma^{2}\left[r^{2}+2 r \alpha+\alpha^{2} \theta\right]+\gamma\left[\alpha^{2} \theta-2(r+\alpha) c\right]-c^{2}
$$

Hence, $\exists \bar{c}>0$ such that $c<\bar{c}$ implies search is viable for $\gamma \in\left[\gamma_{1}, \gamma_{2}\right]$, with $0<\gamma_{1}<\gamma_{2}$; and for $c>\bar{c}$ search is not viable for any $\gamma \geq 0$. As $c \rightarrow 0,\left[\gamma_{1}, \gamma_{2}\right] \rightarrow[0, \bar{\gamma}]$ consistent with (27).

Now consider the FOC from generalized Nash bargaining, $\theta y=\theta V-(1-\theta)[\sqrt{y}-\gamma] 2 \sqrt{y}$. Substituting $V$ and rearranging terms, the steady state $y$ solves

$$
(2-\theta)(r+\alpha) y-[2 \gamma(1-\theta)(r+\alpha)+\alpha \theta] \sqrt{y}+c \theta=0
$$

The solution satisfies

$$
\sqrt{y}=\frac{[2 \gamma(1-\theta)(r+\alpha)+\alpha \theta]+\sqrt{[2 \gamma(1-\theta)(r+\alpha)+\alpha \theta]^{2}-4(2-\theta)(r+\alpha) c \theta}}{2(2-\theta)(r+\alpha)}
$$

Inserting $U=\sqrt{y}$ into the viability condition $\gamma \leq(\alpha U-c) /(r+\alpha)$ and simplifying, we have

$$
\gamma^{2}\left[r^{2}(2-\theta)+2 r \alpha+\alpha^{2} \theta\right]+\gamma\left\{[r(2-\theta)+\alpha] 2 c-\alpha^{2} \theta\right\}+(2-\theta) c^{2} \leq 0 .
$$

Again there exists $\bar{c}>0$ such that $c<\bar{c}$ implies search is viable for $\gamma \in\left[\gamma_{1}, \gamma_{2}\right]$, with $0<\gamma_{1}<\gamma_{2}$; and for $c>\bar{c}$ search is not viable for $\gamma \geq 0$.

One can do the same for Kalai's proportional bargaining solution. At steady state,

$$
\theta y+\frac{[(1-\theta) r+\alpha]}{r+\alpha} \sqrt{y}+\left[\frac{c \theta}{r+\alpha}-\gamma(1-\theta)\right]=0 .
$$

The solution satisfies

$$
\sqrt{y}=\frac{1}{2 \theta}\left\{-[(1-\theta) r+\alpha] /(r+\alpha)+\sqrt{\frac{[(1-\theta) r+\alpha]^{2}}{(r+\alpha)^{2}}-4 \theta[c \theta /(r+\alpha)-\gamma(1-\theta)]}\right\},
$$

and the viability condition is

$$
\gamma^{2}(r+\alpha)^{2} \theta+\gamma\{2 \theta c(r+\alpha)+\alpha[r(1-\theta)-\theta \alpha]\}+c[\theta c+\alpha(1-\theta)] \leq 0
$$

Again, search is viable if and only if $c$ is small.

When $c=0$, the upper bounds for $\gamma$ that allow search are as given in the text. Algebra implies $\bar{\gamma}_{n} \leq \bar{\gamma}_{s}<1$ and $\bar{\gamma}_{k}<1$, while the relationship between $\bar{\gamma}_{k}$ and the others is ambiguous. When $c=0$ and $r=0, \bar{\gamma}_{n}=\bar{\gamma}_{s}=\bar{\gamma}_{k}=1$ independent of $\theta$, and $U$ is given by (28). 


\section{References}

[1] Aiyagari, S. and N. Wallace. 1991. "Existence of Steady States with Positive Consumption in the Kiyotaki-Wright Model," Review of Economic Studies 58, 901-16.

[2] Bayer, P., C. Geissler and J.W. Roberts. 2011. "Speculators and Middlemen: The Role of Flippers in the Housing Market," NBER Working Paper No. 16784

[3] Beal, V. 2009. "EBay Clarifies Buyer and Seller Protection Obligations," online article at http://www.ecommerce-guide.com/article.php/3818976/EBay-Clarifies-Buyerand-Seller-Protection-Obligations.htm

[4] Biglaiser, G. 1993. "Middlemen as Experts," RAND Journal of Economics 24, 212-223.

[5] Binmore, K. 1987. "Perfect Equilibria in Bargaining Models," in The Economics of Bargaining, ed. K. Binmore and P. Dasgupta, Oxford: Blackwell.

[6] Binmore, K. 1992. Fun and Games: A Text on Game Theory. D.C. Health.

[7] Binmore, K., A. Rubinstein and A. Wolinsky. 1986. "The Nash Bargaining Solution in Economic Modelling," RAND Journal of Economics 17, 176-188.

[8] Bose, G. and A. Sengupta. 2010. "A Dynamic Model of Search and Intermediation," Mimeo.

[9] Burdett, K. and M.G. Coles. 1999 "Long-Term Partnership Formation: Marriage and Employment," Economic Journal 109, 307-334.

[10] Burdett, K., and K. Judd. 1983. "Equilibrium Price Dispersion," Econometrica 51, $955-70$.

[11] Butters, G. 1977. "Equilibrium Distributions of Sales and Advertising Prices," Review of Economic Studies 44, 465-491.

[12] Camera, G. 2001. "Search, Dealers, and the Terms of Trade," Review of Economic Dynamics 4, 680-694.

[13] Çinlar, E. 1975. Introduction to Stochastic Processes, Prentice-Hall.

[14] Clippel, G. and K. Eliaz. 2011. "On the Strategic Disclosure of Feasible Options in Bargaining," working paper, Brown University.

[15] Coles, M. and R. Wright. 1998. "A Dynamic Equilibrium Model of Search, Bargaining, and Money," Journal of Economic Theory 78, 32-54.

[16] Coles, M. and A. Muthoo. 2003. "Bargaining in a non-stationary environment," Journal of Economic Theory 109, 70-89. 
[17] Cooke, A. 2000. "New Role for the Middleman," online article at http:// www.isoc.org/inet2000/cdproceedings/7d/7d_3.htm

[18] Diamond, P. 1971. "A Model of Price Adjustment," Journal of Economic Theory 2, 156-168.

[19] Diamond, P. 1987. "Consumer Differences and Prices in a Search Model," Quarterly Journal of Economics 102, 429-436.

[20] Duffie, D., N. Gârleanu and L. Pederson. 2005. "Over-the-Counter Markets," Econometrica $73,1815-1847$.

[21] Ellis, M. "Wholesale Products And The Middleman-Chain," online article at http://blog.motoring-loans.co.uk/wholesale-products-and-the-middleman-chain/

[22] Farhi, E. and J. Tirole. 2010. "Bubbly liquidity," Working Paper.

[23] Gale, D. 1987. "Limit theorems for markets with sequential bargaining," Journal of Economic Theory 43, 20-54.

[24] Gehrig, T. 1993. "Intermediation in Search Markets," Journal of Economics and Management Strategy 2, 97-120.

[25] Johri, A. and J. Leach. 2002 "Middlemen and the Allocation of Heterogeneous Goods," International Economic Review 43, 347-361.

[26] Kalai, E. 1977. "Proportional Solutions to Bargaining Situations: Interpersonal Utility Comparisons," Econometrica 45, 1623-30.

[27] Kalai, E., A. Postlewaite and J. Roberts. 1978. "Barriers to trade and disadvantageous middlemen: Nonmonotonicity of the core," Journal of Economic Theory 19, 200-209.

[28] Kiyotaki, N. and R. Wright. 1989. "On Money as a Medium of Exchange," Journal of Political Economy 97, 927-954.

[29] Kocherlakota, N. 1998. "Money is Memory," Journal of Economic Theory 81, 232-251.

[30] Koper, C. and P. Reuter. 1995. "Suppressing Illegal Gun Markets: Lessons from Drug Enforcement," online article at http://www.publicpolicy.umd.edu/files.php/faculty/ reuter/COOK2.pdf.

[31] Lagos, R., and G. Rocheteau. 2009. Liquidity in Asset Markets With Search Frictions, Econometrica 77, 403-426.

[32] Lagos, R. Rocheteau, G. and Weill, P. 2009. "Crises and Liquidity in Over-the-Counter Markets," Mimeo.

[33] Lagos, R. and Wright, R. 2005. "A Unified Framework for Monetary Theory and Policy Analysis," Journal of Political Economy 113, 463-484. 
[34] Lester, B., A. Postlewaite and R. Wright. 2010. "Information, liquidity, asset prices and monetary policy," Mimeo.

[35] Levine, D. 2010. "Production Chains," NBER working paper 16571

[36] Li, Y. 1998. "Middlemen and Private Information," Journal of Monetary Economics 42, 131-159.

[37] Li, Y. 1999. "Money and Middlemen in an Economy with Private Information," Economic Inquiry 37, 1-12.

[38] MacCleod, B. and J. Malcomson. 1993. "Investments, Holdups, and the Form of Market Contracts," American Economic Review 838, 811-837.

[39] Marchesiani, A. and E. Nosal. 2011. "Private Takings," working paper.

[40] Masters, A. 2007. "Middlemen in Search Equilibrium," International Economic Review $48,343-62$.

[41] Masters, A. 2008. "Unpleasant Middlemen," Journal of Economic Behavior and Organization $68,73-86$.

[42] Miao, J. 2006. "A search model of centralized and decentralized trade," Review of Economic Dynamics 9, 68-92.

[43] Mortensen, D. and R. Wright. 2002. "Competitive Pricing and Efficiency in Search Equilibrium," International Economic Review 43, 1-20

[44] Nash, J. 1950. "The Bargaining Problem," Econometrica 18, 155-162.

[45] Nosal, E. and G. Rocheteau. 2010. Money, Payments, and Liquidity. MIT Press.

[46] Osborne, M. and A. Rubinstein. 1990. Bargaining and Markets. Academic Press.

[47] Ramsay, M. 2006. "The Buyer/Seller Asymmetry: Corrective Justice and Material NonDisclosure," University of Toronto Law Journal 56, 115-149.

[48] Rubinstein, A. and Wolinsky A. 1985. "Equilibrium in a Market with Sequential Bargaining," Econometrica 53, 1133-1150.

[49] Rocheteau, G. and R. Wright. 2010. "Liquidity and Asset Market Dynamics," Working Paper.

[50] Rust, J. and R. Hall. 2003. "Middlemen versus market makers: A theory of competitive exchange," Journal of Political Economy 111, 353-403.

[51] Rubinstein, A. and Wolinsky A. 1987. "Middlemen," Quarterly Journal of Economics $102,581-594$.

[52] Shevichenko, A. 2004. "Middlemen," International Economic Review 45, 1-24. 
[53] Shi, S. 1995. "Money and Prices: A Model of Search and Bargaining," Journal of Economic Theory 67, 467-496.

[54] Smith, E. 2004. "Intermediated Search," Economica 71, 619-636.

[55] Stahl, I. 1972. Bargaining Theory. Stockholm Research Institute.

[56] Shell, K. 1971. "Notes on the Economics of Infinity," Journal of Political Economy 79, 1002-11.

[57] Tse, C. 2009. "The Spatial Origin of Commerce," Mimeo.

[58] Trejos, A. and R. Wright. 1995. "Search, Bargaining, Money, and Prices," Journal of Political Economy 103, 118-141.

[59] Yavas, A. 1992. "Marketmakers versus Matchmakers," Journal of Financial Intermediation 2, 33-58.

[60] Yavas, A. 1994. "Middlemen in Bilateral Search Markets," Journal of Labor Economics $12,406-429$.

[61] Yavas, A. 1996. "Search and Trading in Intermediated Markets," Journal of Economics and Management Strategy 5, 195-216.

[62] Wallace, N. 1980. "The Overlapping Generations Model of Fiat Money," in Models of Monetary Economies, ed. J. Kareken and N. Wallace, Minneapolis: Federal Reserve Bank of Minneapolis.

[63] Wallace, N. 2001. "Whither Monetary Economics?" International Economic Review 42, 847-869.

[64] Watanabe, M. 2010a. "A model of merchants," Journal of Economic Theory 145, 18651889.

[65] Watanabe, M. 2010b. "Middlemen: A Directed Search Equilibrium Approach," Mimeo.

[66] Weill, P. 2007. "Leaning Against the Wind," Review of Economic Studies 74, 1329-1354.

[67] Williamson, S. and R. Wright. 2010a. "New Monetarist Economics: Methods," Federal Reserve Bank of St. Louis Review.

[68] Williamson, S. and R. Wright. 2010b. "New Monetarist Economics: Models," Forthcoming in Handbook of Monetary Economics. 